\title{
WestVirginiaUniversity
}

THE RESEARCH REPOSITORY @ WVU

Graduate Theses, Dissertations, and Problem Reports

2017

\section{A Study of Pressure Variation in Wellbores During Gas Kicks}

Seyhmus Guner

Follow this and additional works at: https://researchrepository.wvu.edu/etd

\section{Recommended Citation}

Guner, Seyhmus, "A Study of Pressure Variation in Wellbores During Gas Kicks" (2017). Graduate Theses, Dissertations, and Problem Reports. 5723.

https://researchrepository.wvu.edu/etd/5723

This Thesis is protected by copyright and/or related rights. It has been brought to you by the The Research Repository @ WVU with permission from the rights-holder(s). You are free to use this Thesis in any way that is permitted by the copyright and related rights legislation that applies to your use. For other uses you must obtain permission from the rights-holder(s) directly, unless additional rights are indicated by a Creative Commons license in the record and/ or on the work itself. This Thesis has been accepted for inclusion in WVU Graduate Theses, Dissertations, and Problem Reports collection by an authorized administrator of The Research Repository @ WVU. For more information, please contact researchrepository@mail.wvu.edu. 


\title{
A STUDY OF PRESSURE VARIATION IN WELLBORES DURING GAS KICKS
}

\author{
Seyhmus Guner
}

Thesis submitted

to the Benjamin M. Statler College of Engineering at West Virginia University

in partial fulfillment of the requirements for the degree of

Master of Science in

Petroleum and Natural Gas Engineering

\author{
H. Ilkin Bilgesu, Ph.D., Chair \\ Samuel Ameri, M.S. \\ Kashy Aminian, Ph.D. \\ Department of Petroleum and Natural Gas Engineering \\ Morgantown, West Virginia \\ 2017
}

Keywords: Gas Rise Velocity, Gas Kick, Pressure Variation in Wellbore, Gas Migration in a Closed Well

Copyright (C) 2017 Seyhmus Guner 


\section{ABSTRACT}

\section{A Study of Pressure Variation in Wellbores During Gas Kick Seyhmus Guner}

It is critical to understand the dynamic behavior and consequences of undesired reservoir influxes that triggers well control emergencies. In contrast to liquid kick, gas influx migration in water based mud and solubility in oil based mud represents exceptionally hazardous conditions. Operation delay time would result in a pressure build-up at the surface with increasing risk of fracturing the casing shoe.

In this study, critical factors affecting gas bubble rise velocity in a closed wellbore are studied. These factors are influx size, annulus clearance, reservoir pressure, oil/water ratio, drilling fluid density, reservoir temperature, plastic viscosity and yield point. Three different well types (vertical, directional and horizontal), well deviation angle and wellbore configurations are considered. Gas rise velocity and pressure changes at the surface and bottom hole are monitored at different well shut-in periods. A commercial multiphase dynamic well control simulator utilized with a common well configuration.

Preliminary results show that higher gas rise velocities and wellbore pressures were experienced as the severity of the encountered conditions increase due to high reservoir pressure as well as the influx size. In comparison to vertical and directional wells, horizontal wellbore trajectory experienced the lowest surface and bottom hole pressures. The average gas rise velocity in WBM was $82.2 \mathrm{ft} . / \mathrm{min}$, while in OBM the average gas rise velocity was $31.96 \mathrm{ft} . / \mathrm{min}$. In addition, in OBM while the gas was migrating to the surface, wellbore pressure increases then free gas dissolves completely and stays stationary. 


\section{ACKNOWLEDGEMENT}

This research was initiated by Dr. H. Ilkin Bilgesu, who provided insight and expertise that greatly assisted the research to investigate the effect of gas kick migration on wellbore annular pressures in a closed wellbore. I would like to thank to him because he consistently advised and helped me with his great knowledge and valuable comments for this study, he steered me in the right direction whenever he thought I needed it.

A special thanks to Turkish Petroleum Corporation for sponsoring and supporting me to study in an outstanding university in the United States of America. I would also like to thank my parents for never stopping their support for me during my study.

I am very thankful to Chairman, Petroleum and Natural Gas Engineering Department, Prof. Samuel Ameri for being as a committee member, his assistance and encouragement during my study at WVU. I would also like to thank to Dr. K. Aminian for serving as committee member.

I would like to thank to Tawfik Elshebabi for his great help on well control applications that greatly improved the manuscript. 


\section{Table of Contents}

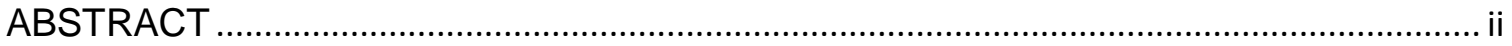

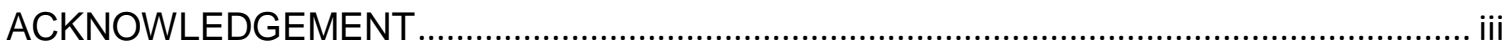

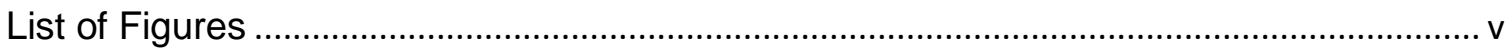

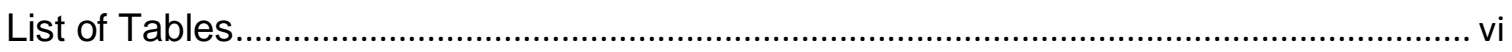

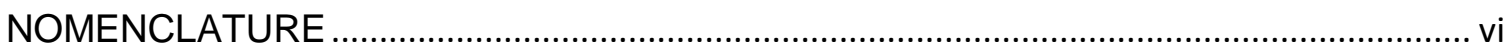

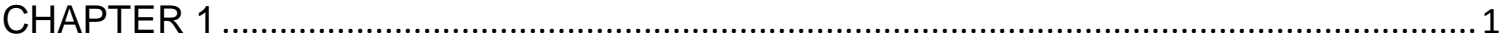

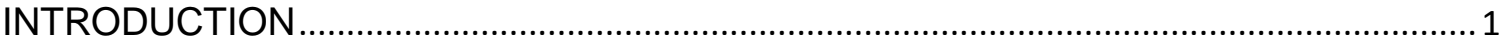

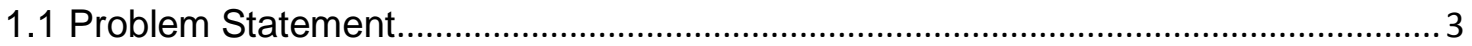

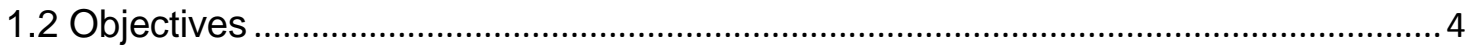

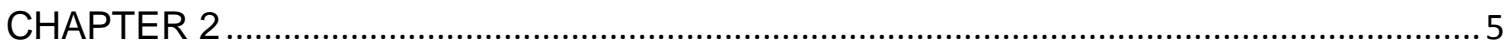

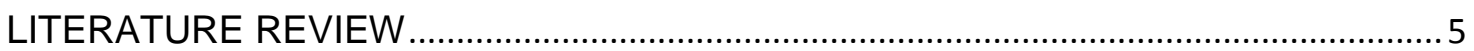

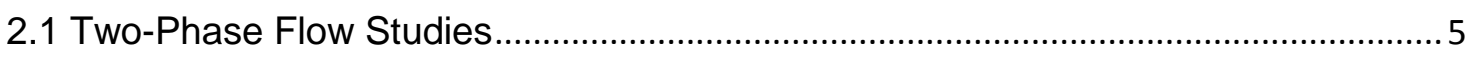

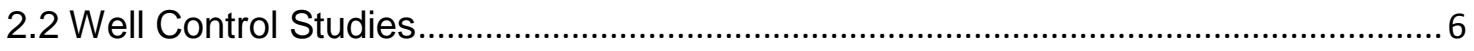

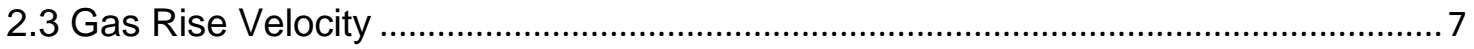

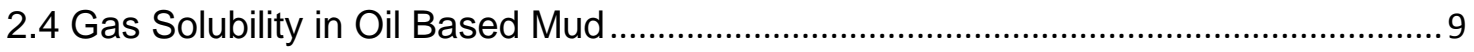

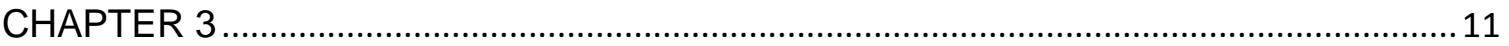

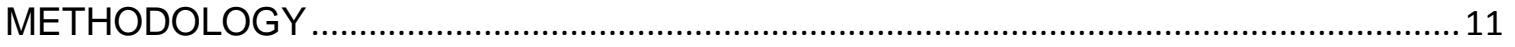

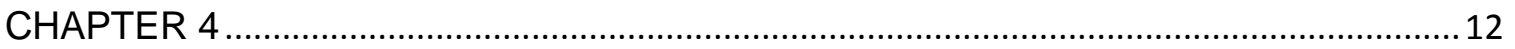

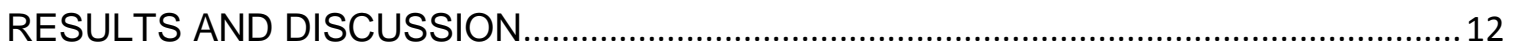

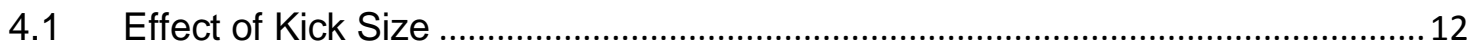

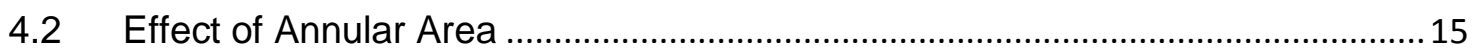

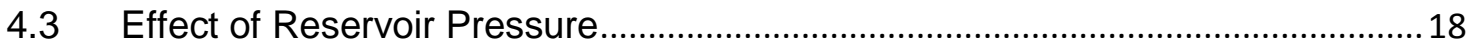

4.4 Effect of Drilling Fluid Type and Density ............................................................ 22

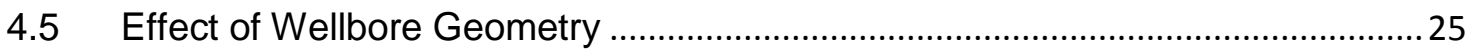

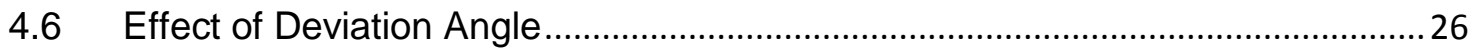

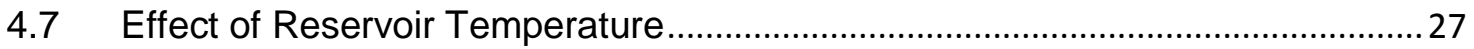

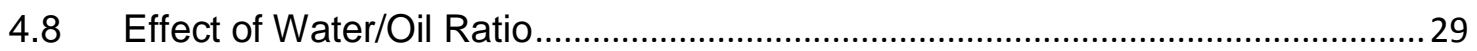

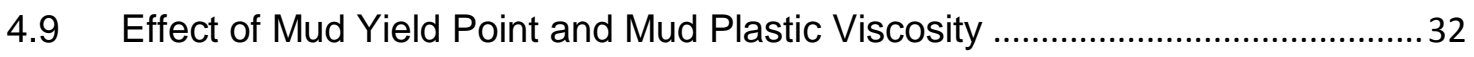

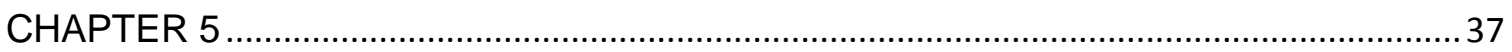

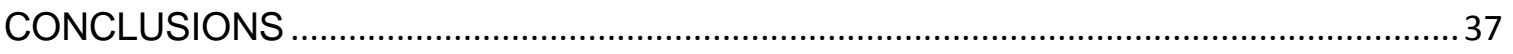

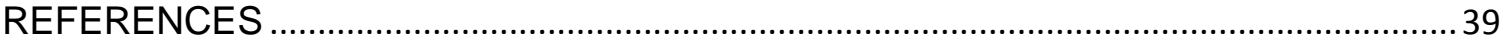


A-1 Example of Modelling in the Simulator

A-2 3-D View of Horizontal, Deviated, and Vertical Well ................................................ 48

A-3 Mud Plastic Viscosity and Yield Point Calculations.....

\section{List of Figures}

Figure 1 Effect of kick size on pressures in a vertical well with OBM......................................... 13

Figure 2 Gas kick dissolution depths for different kick sizes in OBM. ....................................... 14

Figure 3 Effect of kick size on pressures in a vertical well with WBM........................................ 15

Figure 4 Vertical wellbore geometry .................................................................................... 17

Figure 5 Effect of annular clearance on pressure variation in a vertical well with WBM. ..17 Figure 6 Variation of surface and bottomhole pressures for three different reservoir pressures in

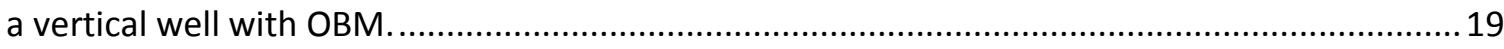

Figure 7 Effect of reservoir pressure on dissolved gas distribution in a wellbore.........................20 Figure 8 Variation of surface and bottom hole pressures for three different reservoir pressures in

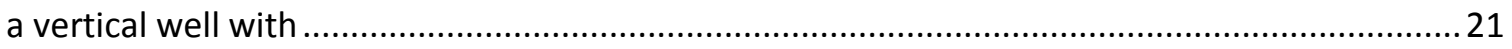

Figure 9 Variation of pressures with time in a vertical well for Oil Based Mud Density. ..............23 Figure 10 Variation of pressures with time in a vertical well for Water Based Mud Density........24 Figure 11 Variation of pressures with time in a vertical well with OBM and WBM.....................25 Figure 12 Variation of pressures with time in a well with WBM for three different wellbore trajectories.

Figure 13 Variation of choke pressures with time in a well with WBM for different wellbore

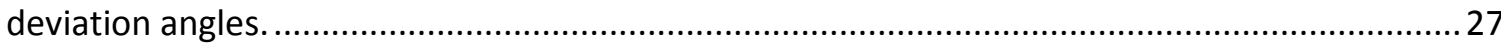

Figure 14 Methane solubility in diesel fuel (Thomas et al. 1984) ................................................28

Figure 15 Variation of pressures with time in a well with OBM for three different reservoir temperatures.

Figure 16 Variation of pressure with time in a deviated well for three different Oil/Water ratios.

Figure 17 Dissolved gas depth and dissolved gas mass fraction for three different oil/water ratios.

Figure 18 Effect of oil/water ratio on the methane solubility in an emulsion (Monteiro. 2005).. 31 Figure 19 Variation of pressure with time in a deviated well for three different mud yield points.

Figure 20 Variation of pressure with time in a deviated well for three different mud plastic viscosities. 33

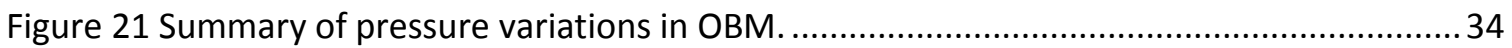

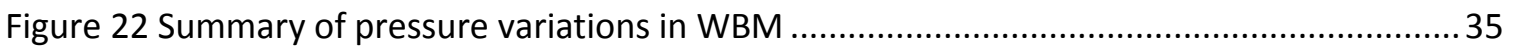

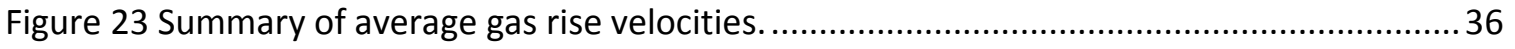

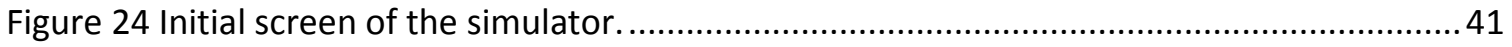

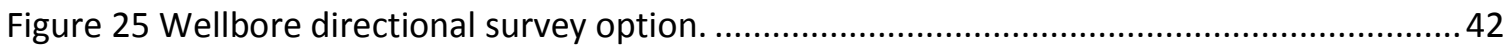

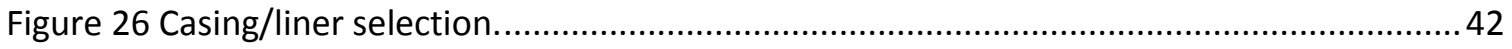




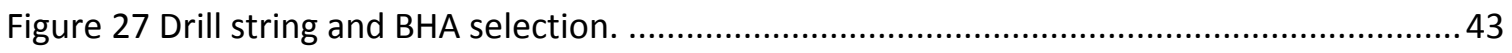

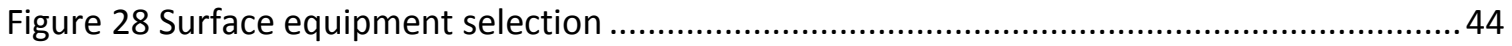

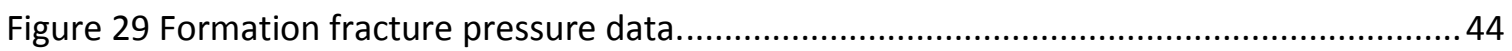

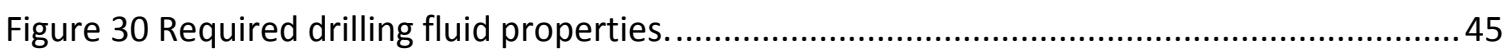

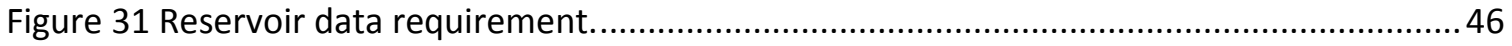

Figure 32 Reservoir temperature assignment. .................................................................... 46

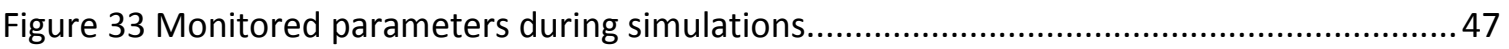

Figure 34 3-D view of horizontal, deviated, and vertical well trajectories................................... 48

Figure 35 Range of YP and PV for a given mud weight........................................................ 49

\section{List of Tables}

Table 1 Wellbore and drill string data

\section{NOMENCLATURE}

\begin{tabular}{|l|l|}
\hline Psi & Pressure per Square Inch \\
\hline ID & Inner Diameter \\
\hline OD & Outer Diameter \\
\hline DP & Drill Pipe \\
\hline DC & Drill Collar \\
\hline HPHT & High Pressure High Temperature \\
\hline F & Fahrenheit \\
\hline SSC & Sulfide Stress Cracking \\
\hline HSS $_{s}$ & Hydrogen Sulfide \\
\hline WBM & Water Based Mud \\
\hline OBM & Oil Based Mud \\
\hline Ft & Feet \\
\hline Min & Minute \\
\hline Gal & Gallon \\
\hline Bbl & Barrel \\
\hline S & Second \\
\hline Ppg & Pound per Gallon \\
\hline Ibm & Pound \\
\hline BOP & Blowout Preventer \\
\hline TVD & True Vertical Depth \\
\hline MD & Measured Depth \\
\hline KOP & Kick off Point \\
\hline PV & Plastic Viscosity \\
\hline YP & Yield Point \\
\hline Cp & Centipoise \\
\hline Ft ${ }^{2}$ & Squared Feet \\
\hline BHA & Bottom Hole Assembly \\
\hline & \\
\hline
\end{tabular}




\section{CHAPTER 1}

\section{INTRODUCTION}

Drilling is a part of oil exploration and extraction process and the only way to produce oil and gas. The first oil well drilled more than 150 years ago, but lots of problems arose during drilling. Since then, the drilling industry has been innovating to drill deeper in a safe manner, which is an expensive process (Imomoh, 2013). Companies spend millions of dollars for on-shore and off-shore drilling. For this reason, drilling cost and drilling safety should be considered as two main factors in drilling applications. These two factors are highly related to each other. Drilling a well without accidents demands safety investments, which requires high drilling costs. However, companies are inclined to avoid high drilling costs. Reducing drilling costs impacts safe drilling. Drilling without any problem and costs associated with drilling must be in the balance with appropriate well programming (Stromsnes et al. 1995). For an exploration well, it is preferred high drilling safety regulations since it is in an unproven area.

In oil and gas industry, to drill a well without any accidents and problems requires proper well control. Well control is to maintain monitoring of the well during flow or kick to minimize the potential of kick reach to the surface or to permit it to reach to surface under control. In other words, well control is preventing the fluid flow from the formation into well caused by pressure differences between the formation and well with proper technics. Well control includes drilling hydraulics and wellbore pressure monitoring, well design, drill string design, casing design, mud type selection, well head equipment, completion and workover operations. The lack of effective well control can cause significant emergency scenarios, such as: blowout, stuck pipe, lost circulation etc. (Maia and Lima. 2012). 
Most of the fatal accidents in the oil industry occur due to the lack of well control awareness. A kick is a well control problem in which the pressure found within the drilled rock is higher than the mud hydrostatic pressure acting on the borehole or rock face. When this occurs, the greater formation pressure has a tendency to force formation fluids into the wellbore. This forced fluid flow is called a kick. If the flow is successfully controlled, the kick is considered to have been killed. An uncontrolled kick that increases in severity may result in what is known as a "blowout." (Veeningen, 2013). The most common kick causes are insufficient mud weight, improper hole fill up, swabbing, cut mud, and lost circulation. Improper actions such as equipment failure and lack of crew awareness could result in uncontrolled surface or underground blowouts.

Surface blowouts mostly cause oil spills and explosion in the rig as seen in the 2010 Macondo blowout (Sutton, 2013). Gas migration in the well can be disperse flow from wellbore fluid or mixed with wellbore fluid. In disperse flow, the gas expands and moves faster while it migrates to the surface. In mixture flow, gas in solution comes out of oil based drilling fluid. Gas dissolves in oil based drilling fluid at a certain pressure and temperature and it may migrate with drilling fluid or suspends in drilling mud depending on gas kick concentration. At one point, gas bubbles in solution come up as free gas, and it reaches to the top of the well as free gas bubbles (Hovland and Rommetveit. 1992). It is difficult to detect and handle gas migration in a well. Therefore, gas blowouts are known as more dangerous than oil blowouts.

Wellbore pressure monitoring during drilling operations plays a crucial role in awareness of any pressure change in the wellbore. Knowledge of wellbore pressure provides significant clues and helps to avoid formation damage caused by exceeding formation fracture pressure or flow of formation fluid into the wellbore due to minimal hydrostatic pressure. Having accurate wellbore pressure measurements will prevent the 
occurrence of non-productive time events by providing an earlier warning that a problem is developing. Well control philosophy is based on maintaining a constant bottom hole pressure throughout kick handling procedures. Once an influx is detected at the surface, the BOP is closed to minimize influx volume. Then, upon shutting-in the wellbore and stabilizing the shut-in drill pipe and casing pressures, a proper kick circulating method is applied. This includes circulating the influx and displacing higher mud density in the wellbore to overbalance the kicking zone (Watson et al. 2003). If the crew fails to start influx circulation, gas bubbles percolate in a closed wellbore to the surface due to density difference. While gas bubbles migrate in water based mud, the wellbore pressures increase (Guner et al. 2016).

Consequently, if the formation fracture pressure or surface equipment pressure rating is exceeded, an inevitable blowout will be triggered. Gas is highly soluble in oilbased mud and as a result surface pressure and volume measurements are not representative of the actual downhole measurements (Elshehabi and Bilgesu. 2015). It makes a significant difference between pit gain volume and actual kick volume in downhole. Therefore, it is necessary to investigate critical factors affecting gas bubble rise velocity in water and oil based drilling fluids to prevent any catastrophic accidents during drilling operations.

\subsection{Problem Statement}

The major problem addressed in this study is to determine the impact of wellbore pressure variations and gas rise velocities due to gas migration in a closed wellbore. In this study, it is assumed that formation pressure is higher than wellbore hydrostatic pressure for each case in order to obtain a gas kick in the wellbore from the formation. Oil based and water based muds are used to determine the factors affecting pressure 
build up in the wellbore. Vertical, directional and horizontal well types are considered with different annulus sizes.

Monitoring wellbore pressure variations provides a mechanism to maintain or increase wellbore integrity and optimize drilling operation. Any undesirable change of wellbore pressure might be related to serious wellbore problems, which can threat wellbore integrity (Savari and Kumar, 2012). Therefore, this study investigates wellbore pressure variations and factors affecting wellbore annular pressures and gas rise velocities due to gas kick migration in a closed well in order to maintain wellbore integrity and proper drilling practices.

\subsection{Objectives}

The purpose of this study was to investigate the factors affecting wellbore annular pressure and gas rise velocity due to gas kick migration in a closed wellbore. In order to achieve this objective, the following steps were preformed:

- A comprehensive literature review for better understanding about gas kick migration in a closed wellbore.

- Development of simulation models for the determination of factors affecting wellbore annular pressures and gas rise velocities.

- Conducting runs with simulation models.

- Analyzing the results of simulation model runs to understand wellbore pressure variations and change in gas rise velocities due to gas migration. 


\section{CHAPTER 2}

\section{LITERATURE REVIEW}

\subsection{Two-Phase Flow Studies}

Gas kick behavior based on unsteady-state two-phase mixture flow was analyzed by Choe (2001) using simulation of a dynamic two-phase well control model He stated that temperature, pressure, liquid and gas fractions, densities and velocities affected two-phase flow system. Gas slip velocity is crucial to make an estimation of the time for maximum choke pressure and choke pressure is related to kick height in the annulus. For that reason; the effect of annulus clearance on kick size should be considered as an important parameter. It is also concluded that mud compressibility is another important parameter, which should be considered for pressure build up after the well is shut-in.

A two-phase flow in vertical and inclined annuli is studied by Hasan at. al. (2009) using air-water and air-mud two-phase flow models. They found that the influence of the well deviation on gas slip velocity is the most significant difference between two models. Gas slip velocity increases as the well deviates from vertical in the air-mud model. On the contrary, inclination effect was considered as gravity effect in the air-water model.

The pressure gradient is an important parameter to design two-phase flow simulation. Pressure loss is much greater than it is thought since energy transfer might occur between the phases. Slippage and mass transfer between phases, and change of flow pattern make the two-phase flow a complicated phenomenon. Beggs and Brill (1973) stated that the angle of the pipe has a significant impact on liquid holdup and pressure drop. Liquid holdup reaches the peak at $+50^{\circ}$ and drops to a minimum at $-50^{\circ}$ 
from horizontal. The liquid holdup has great impact on frictional pressure loss (Beggs and Brill. 1973).

Gould et al. (1974) investigated the pressure drop models by classifying flow regimes and examined the effect of pipe geometry. They computerized a method, which determines the flow regime first, then predicts the friction, density and acceleration gradients for flow regime. Pressure profiles for an entire pipe can be predicted if the geometry of pipe and physical properties of the two-phase flow system are known. Coexistence of many flow regimes such as; single-phase liquid flow, two-phase bubble flow, slug flow, transition flow and mist flow in the entire length of the pipe was the essential reason for the failure of most of the previous studies on two-phase flow correlations. Contrary to previous studies, they asserted that pipe inclination does not have a significant impact on flow regime (Gould et al. 1974).

\subsection{Well Control Studies}

Recently, simulators have been implemented in drilling and well control planning and operations. For instance, in planning it evaluates different designs with specified limits and in operations it supports critical decisions ( $\mathrm{Ng}, 2005)$. A constant bottom-hole pressure is the main objective in well control based on the U-tube model to avoid secondary kicks. The basic advantage of applying Driller's method (also called two circulation method) is to avoid waiting time for mud preparations. In contrast, Wait-andWeight (also called one circulation or Engineer's) method requires only one circulation and would decrease wellbore pressures if heavy mud reaches annulus before gas is circulated out. However, during waiting time for mud preparation gas migrates and pressurizes the wellbore (Adams and Kuhlman, 1994) 
Drilling crew sometimes is forced to wait on kick circulation as a result of pump failure or drill string is outside the hole during well control situation. Therefore, Matthews and Bourgoyne (1983) proposed the implementation of constant drill pipe pressure, static and dynamic volumetric methods when normal well control methods are delayed to minimize gas migration consequences. In Gulf of Mexico, the Macondo well accident is a recent example of well control emergency. The reduction of hydrostatic pressure was reported due to salt water displacement for temporary abandonment. The crew failed to recognize the increase in return flow rate that was a positive indicator of a kick and it was too late to close BOPs properly. Hence, it resulted in a catastrophe where there were loss of human lives (Fjelde et al., 2016, April 20).

\subsection{Gas Rise Velocity}

Gas rise velocity is one of the critical parameters in well control operations. Experimental study by researchers (Rader et al., 1985) showed that the inside and outside diameters of annulus, gas expansion, deviation angle, gas and liquid densities were the most essential factors affecting velocity of large bubbles.

The yield stress of drilling mud has a substantial impact on gas bubbles suspension in the same manner how it affects drilling cuttings to be held in the drilling mud. Gas concentrations larger than $10 \%$ migrates fast as big bubbles around 100 $\mathrm{ft} / \mathrm{min}$. However, low concentration of gas migrates slowly and as small bubbles, and migration would be suspended where the gas in mud remains stationary. The low concentration of gas remains stationary unless gas cut mud is circulated out. Therefore, there is no definite rule for gas velocity. It is much more related to gas concentration and yield stress of the drilling mud (Johnson et al., 1995). 
Hovland and Rommetveit (1992) examined gas kick migration with experiments in OBM and WBM in large scale inclined well. They observed that low and medium concentration of gas kicks rise slower than high concentration gas kicks, and gas rise velocity is substantially related to wellbore inclination and mud rheology. Similarly, Johnson and Cooper (1993) claim that wellbore inclination and geometry of the well has a critical impact on gas rise velocities. They made tests using pipe orientations between vertical and $60^{\circ}$ deviations. They concluded that slip velocity increases as the deviation of pipe increases. Slip velocity increases more for small deviations. After $45^{\circ}$, slip velocity starts decreasing to its vertical value. From $45^{\circ}$ to $60^{\circ}$, bubbles distort the liquid velocity at the top of the pipe. They also inferred that estimation of gas migration velocity would be wrong by evaluating shut-in surface pressure rise rate since it neglects the impact of mud compressibility, wellbore elasticity, and fluid loss. Likewise, Fjelde ( 2016) and his colleagues examined gas kick migration velocities in a closed well. They estimated the gas rise velocity as $45.3 \mathrm{ft} / \mathrm{min}$. They asserted that there might be possible errors due to the uncertainties or uncertainty associated with gas slip parameters. They claimed that using the pressure build up gradients for the estimation of the gas rise velocity may show different results since the gas trapped in the mud may affect the pressure build up gradients in a closed well.

In a closed wellbore with high $\mathrm{pH}$ drilling fluids, percolation of sour gas influxes creates chemical buffering reaction that damages high strength steel pipes. Shen et al. (2013) derived a model that estimates gas rising speed and kick exerted forces considering the effect of downhole temperature. Moreover, hydrogen sulfide influx into high $\mathrm{pH}$ mud creates sulfide stress cracking (SSC) to drill string because of chemical reaction-kinetic effects during well shut-in period. Upward gas migration is accompanied with potential change in flow pattern and corrosion severity. Likewise, the amounts of 
dissolved $\mathrm{H}_{2} \mathrm{~S}$ gas will continue to contact with drill pipe (Mason and Chandrasekhar, 2015). In their study about dynamic behavior of gas expansion in marine riser, Velmurugan et al. (2016) concluded that buoyancy and slip cause gas migration. Also, hydrostatic pressure decrease triggers gas expansion until enough back pressure is applied.

\subsection{Gas Solubility in Oil Based Mud}

Although WBM is known as the most common drilling fluid, the features of WBM make it inconvenient type of mud for HPHT wells due to the evaporation of water. Wells have pressure above 10000 psi and temperature above $300^{\circ} \mathrm{F}$ can be considered as HPHT well. It is hard to detect gas kick during drilling with OBM. Adams and Kuhlman (1994) stated that pit gain is not an accurate indicator when OBM is used because gas dissolves in oil and pit gain does not represent the actual kick size. Therefore, gas kick can reach to surface without any surface warning signs. For instance, 20 bbl of a gas kick can be detected as $4-6$ bbl surface pit gainin OBM. Remarkably, gas fraction is trapped and remains stationary in HPHT wells drilled with oil based mud because of mud yield point in a closed well.

Methane solubility in diesel, mineral, synthetic, and ester oils was studied by Berthezene et al. (1999). They concluded that gas is fully miscible when pressure is above the miscibility pressure. Mason and Chandrasekhar (2015) analyzed gas kick behavior by considering mud compressibility and gas solubility with the change of pressure and temperature in $20 \mathrm{k}$ and $30 \mathrm{k} \mathrm{ft}$. of offshore wells with OBM. It is stated that temperature has a higher influence on the mud density than pressure has. They also inferred that while the gas kick rises to the surface, kick volume decreases because of temperature and pressure effect on gas solubility. O'Bryan et al. (1988) concluded that gas solubility increases with the higher pressure and specific gravity of gas. However, 
gas solubility decreases with higher temperature and solid contents. For that reason, they concluded that pit volume may not be a good indicator of gas kick. Velmurugan et al. (2016) asserted that influx detection in oil based mud is complicated due to complete dissolution of gas and relative delay in surface kick indicators. On the contrary, Thomas et al. (1984) claimed that pit gain is most reliable kick indicator for both WBM and OBM even though pit gain is much smaller for OBM than WBM. They recommended that pit gain alarm should be set for less than $5 \mathrm{bbl}$. for early detection of kick. They stated that flow check is not a reliable indicator of kick for OBM since gas dissolves in OBM. Initial kick volume might be too small and it takes approximately 10 minutes to detect kick in OBM when mud pumps are shut down. 


\section{CHAPTER 3}

\section{METHODOLOGY}

In this study, a two phase dynamic well control software is used to investigate the factors that affect gas bubble rise in a closed well drilled with water or oil based drilling fluids. Impact on choke, casing shoe, and bottomhole pressures after the well has been shut-in are monitored to avoid fracturing the casing shoe. The parameters that were studied are kick size, wellbore annulus clearance, reservoir pressure, drilling fluid density, wellbore geometry (for vertical, directional and horizontal wells), oil/water ratio, mud yield point and mud plastic viscosity.

Kick sizes of $10 \mathrm{bbl}, 20 \mathrm{bbl}$ and $30 \mathrm{bbl}$ are used with water and oil based mud to understand how kick size impacts wellbore pressures and gas rise velocity. Three different wellbore annular areas with 5.0", 6.276", and 8.0" casing inside diameters and $3 \frac{1}{2}$ " drill pipe outside diameter are used to find out the influence of wellbore geometry. Reservoir pressures of 5,500 psi, 6,500 psi, and 7,500 psi are used. $11.20 \mathrm{lbm} / \mathrm{gal}$, $13.35 \mathrm{lbm} / \mathrm{gal}$, and $15.52 \mathrm{lbm} / \mathrm{gal}$ water and oil based muds are used to compare the effects of drilling fluid density. Vertical, horizontal and deviated wells are used as types of wellbore geometry to determine their impact. True vertical depth (TVD) of $6,824 \mathrm{ft}$ is used for each type of well as a reference depth for the reservoir and casing shoe depth was $5,708 \mathrm{ft}$. The measured depths (MD) of horizontal and deviated wells were $14,928 \mathrm{ft}$ and $7,098 \mathrm{ft}$ respectively. Average gas rise velocity is calculated based on migration time and measured depth after gas percolated to surface. To see the impact of oil-water ratio (O/W) for OBM; 50/50, 70/30 and 90/10 O/W ratios were used. In addition, Bingham Plastic models were used with the yield point of $5 \mathrm{lbm} / 100 \mathrm{ft}^{2}, 10 \mathrm{lbm} / 100 \mathrm{ft}^{2}, 15$ $\mathrm{lbm} / 100 \mathrm{ft}^{2}$. Also, the plastic viscosity of $12 \mathrm{cp}, 19 \mathrm{cp}$, and $26 \mathrm{cp}$ with $13.35 \mathrm{lbm} / \mathrm{gal}$ WBM were used to see the impact of drilling fluid's rheological properties on wellbore pressures. 


\section{CHAPTER 4}

\section{RESULTS AND DISCUSSION}

The results are obtained by running a simulation model that uses a dynamic well control. The pressure variations for surface choke, bottomhole and casing shoe for each case are shown in the following figures. The average gas rise velocities for each case are shown in Table 2.

\subsection{Effect of Kick Size}

The impact of different kick sizes is studied with OBM and WBM in a vertical well. For OBM, the kick sizes measured as the surface pit gain volumes of $10 \mathrm{bbl}, 20 \mathrm{bbl}$ and 30 bbl. While, for WBM, kick sizes were $5 \mathrm{bbl}, 10 \mathrm{bbl}$ and $15 \mathrm{bbl}$. Figure- 1 shows the impact of kick size on surface and downhole pressures in OBM. Gas solubility takes place when OBM is used as the drilling fluid. A certain amount of gas dissolves in OBM depending on OBM composition, temperature, and pressure. For instance, $10 \mathrm{bbl}$ gas kick migrated to $4,000 \mathrm{ft}$ and increased the wellbore pressures then it completely dissolved and stayed stationary. Figure- 2 shows the final depth of dissolved gas for three different kick sizes. Yellow color represents dissolved gas in the annulus of the well. In addition to pressure related solubility, there is also the effect of entrapment by mud yield point similar to the entrapment of drilling cuttings. 


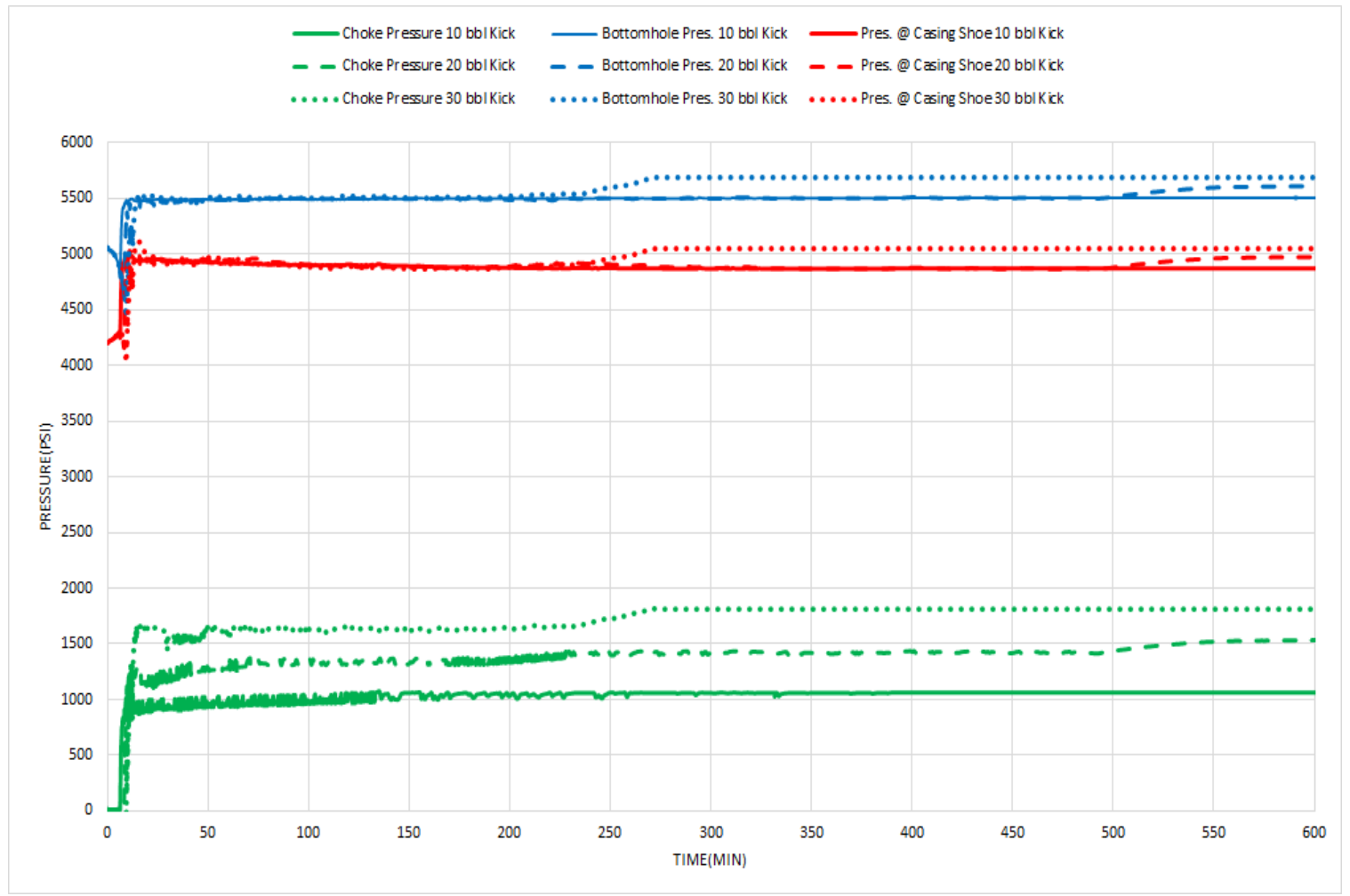

Figure 1 Effect of kick size on pressures in a vertical well with OBM.

Approximately $80 \%$ of the $20 \mathrm{bbl}$. and $30 \mathrm{bbl}$. kick sizes dissolved in the mud while migrating and the rest of the gas migrated in the free gas form and reached the top of the well with different velocities. In comparison to the bottomhole and casing shoe pressures, the choke experienced the highest pressure difference as shown in Figure-1. For example, the choke pressures were 1064 psi, 1533 psi and 1812 psi for 10, 20, and $30 \mathrm{bbl}$. kick sizes, respectively. The average gas rise velocities were $14.1 \mathrm{ft} / \mathrm{min}, 14.22$ $\mathrm{ft} / \mathrm{min}$ and $30.96 \mathrm{ft} / \mathrm{min}$ for $10 \mathrm{bbl}, 20 \mathrm{bbl}$, and $30 \mathrm{bbl}$ kicks. The gas kick arrived at the top of the well around 220 min for 30 bbl. kick size, which was 260 minutes earlier than 20 bbl. kick size. The arrival time was observed on choke pressure curves (Figure-1). There was a second increase on choke pressure curves of 20 and 30 bbl kick sizes as the free gas arrived at the top of the well. And there is no second increase on the choke pressure curve of $10 \mathrm{bbl}$ kick size since gas arrived at the surface while in solution. The 
average gas rise velocity for $30 \mathrm{bbl}$. kick size was more than two folds of the average gas rise velocity for $20 \mathrm{bbl}$. It can be concluded that greater the kick size, higher the gas rise velocity and wellbore pressures.

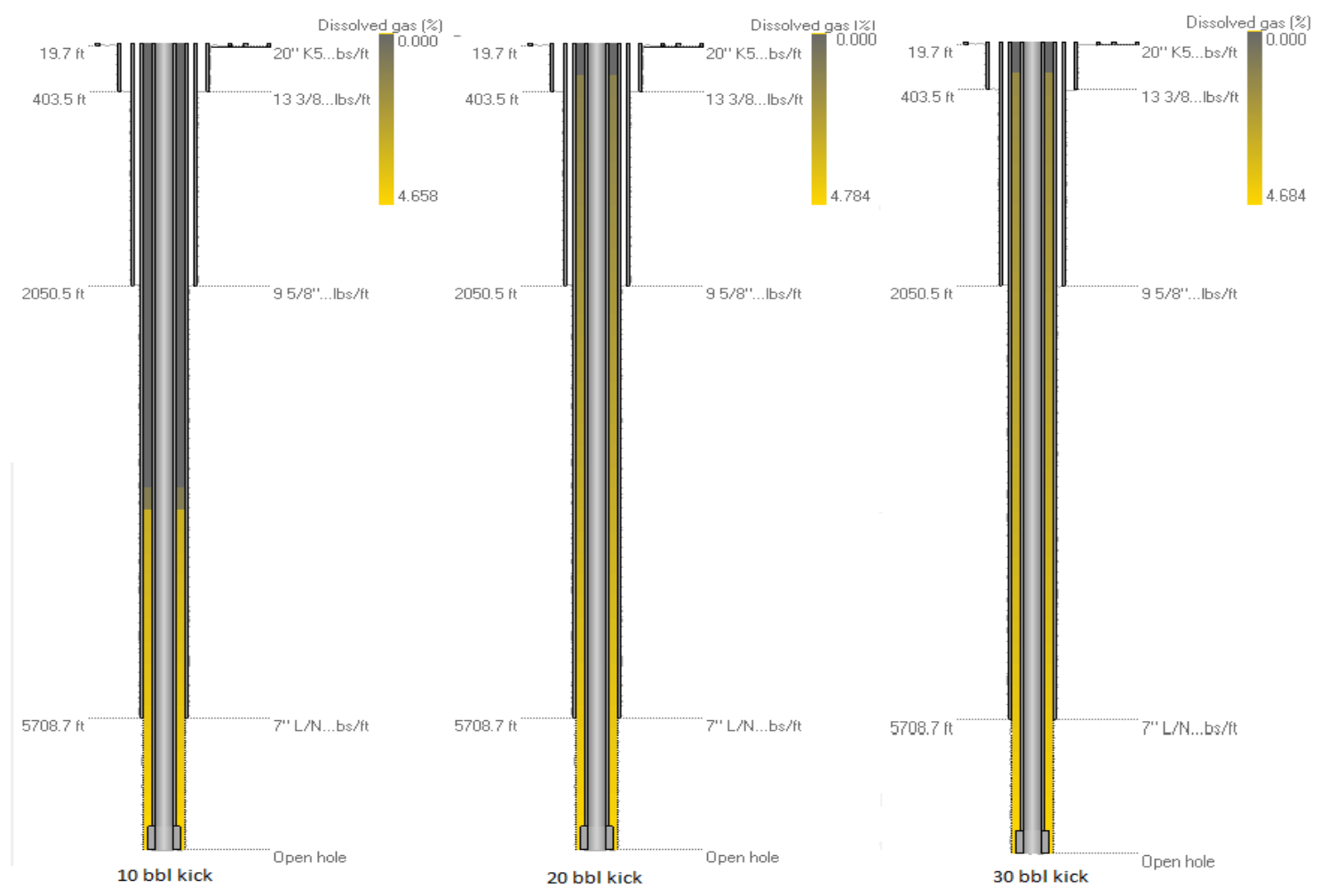

Figure 2 Gas kick dissolution depths for different kick sizes in OBM.

Figure-3 compares pressure variations due to different kick sizes in WBM. Since gas solubility in WBM is insignificant, smaller kick sizes are used in comparison to OBM. In WBM, the whole influx is in the free gas form which migrates and reaches the surface. Therefore, $5 \mathrm{bbl}, 10 \mathrm{bbl}$, and $15 \mathrm{bbl}$ kick sizes were simulated in WBM. The average gas rise velocities were $64.8 \mathrm{ft} / \mathrm{min}$ for $15 \mathrm{bbl}, 55.8 \mathrm{ft} / \mathrm{min}$ for $10 \mathrm{bbl}$, and $46.8 \mathrm{ft} / \mathrm{min}$ for $5 \mathrm{bbl}$ kick size. This means gas arrived at surface 40 minutes earlier for 15 bbl kick size than it arrived for 5 bbl kick size for a vertical well with $6824 \mathrm{ft}$. TVD. It is obvious that gas migrates faster in bigger kick sizes. This observation was consistent with the results observed in OBM. Not only gas rise velocity was higher for bigger kick sizes, but 
wellbore pressures were also greater for bigger kick sizes. For example, 15 bbl kick size created 4310 psi pressure at the choke, which was 440 psi greater than pressure created by $10 \mathrm{bbl}$ kick size. Also, in comparison to $5 \mathrm{bbl}$ kick size, $15 \mathrm{bbl}$ created 1210 psi additional pressure at choke.

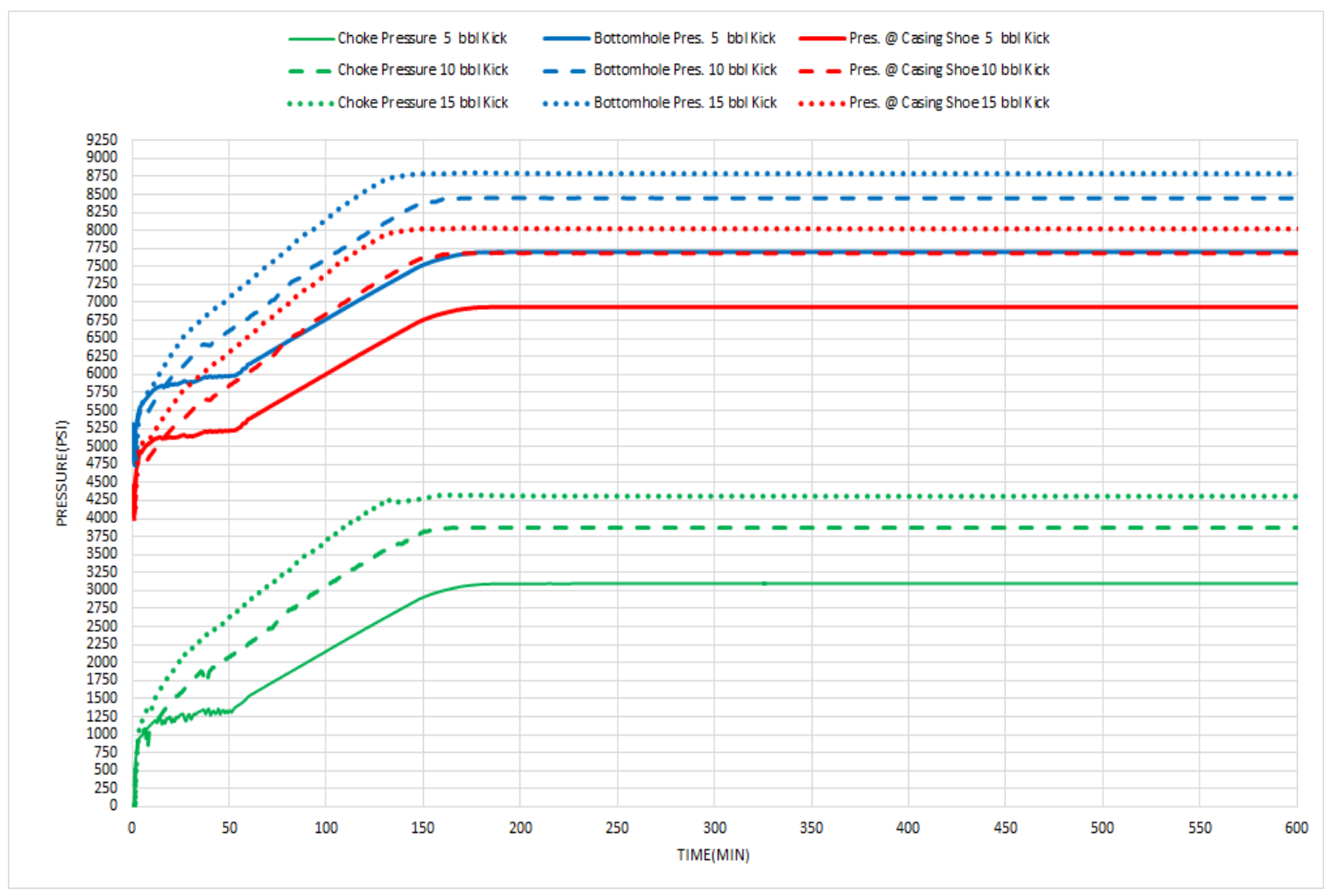

Figure 3 Effect of kick size on pressures in a vertical well with WBM.

\subsection{Effect of Annular Area}

The effect of annular area on surface and downhole pressures and gas rise velocity was investigated using the three different annular clearances shown in Table-1. For all wellbore configurations (Figure-4), $13.35 \mathrm{lbm} / \mathrm{gal}$ WBM was used. Figure-5 presents bottomhole, casing shoe and wellhead choke pressure responses for three different annular areas. In fact, the smaller the annular clearance, the higher was the impact on pressure variation. In smaller annulus clearance, the gas kick column 
occupied longer height compared to larger annulus clearance. For example, surface choke pressure was $4433 \mathrm{psi}$ for the narrowest annulus size. While the choke pressure was 3783 psi for the middle and 2393 psi for the largest annulus clearance.

Table 1 Wellbore and drill string data

\begin{tabular}{|c|c|c|c|}
\hline PROPERTY & Well\#1 & Well\#2 & Well\#3 \\
\hline Casing OD (in.) & 5.500 & 7.000 & 8.625 \\
\hline Casing ID (in.) & 5.012 & 6.276 & 8.016 \\
\hline Drill pipe OD (in.) & 3.500 & 3.500 & 3.500 \\
\hline Drill collar OD (in.) & 4.000 & 4.500 & 4.500 \\
\hline Casing OD (in.) & 4.500 & 6.000 & 7.000 \\
\hline
\end{tabular}

The results are in agreement with the earlier study by Rader et. al. (1985). Tight annular clearance also affected the gas rise velocity in the same way for each wellbore configuration. The gas rise velocity in the smallest annulus clearance was $70 \%$ higher compared to the largest annulus clearance. The gas rise velocities were $82.2 \mathrm{ft} / \mathrm{min}, 54.6$ $\mathrm{ft} / \mathrm{min}$ and $48.6 \mathrm{ft} / \mathrm{min}$ for Well\#1, Well\#2, and Well\#3, respectively. The observed pressure fluctuations shown in Figure- 5 can be attributed to different annular areas in the wellbore. This includes annular area between DC and open hole, DP and open hole, DP and previous casing. 

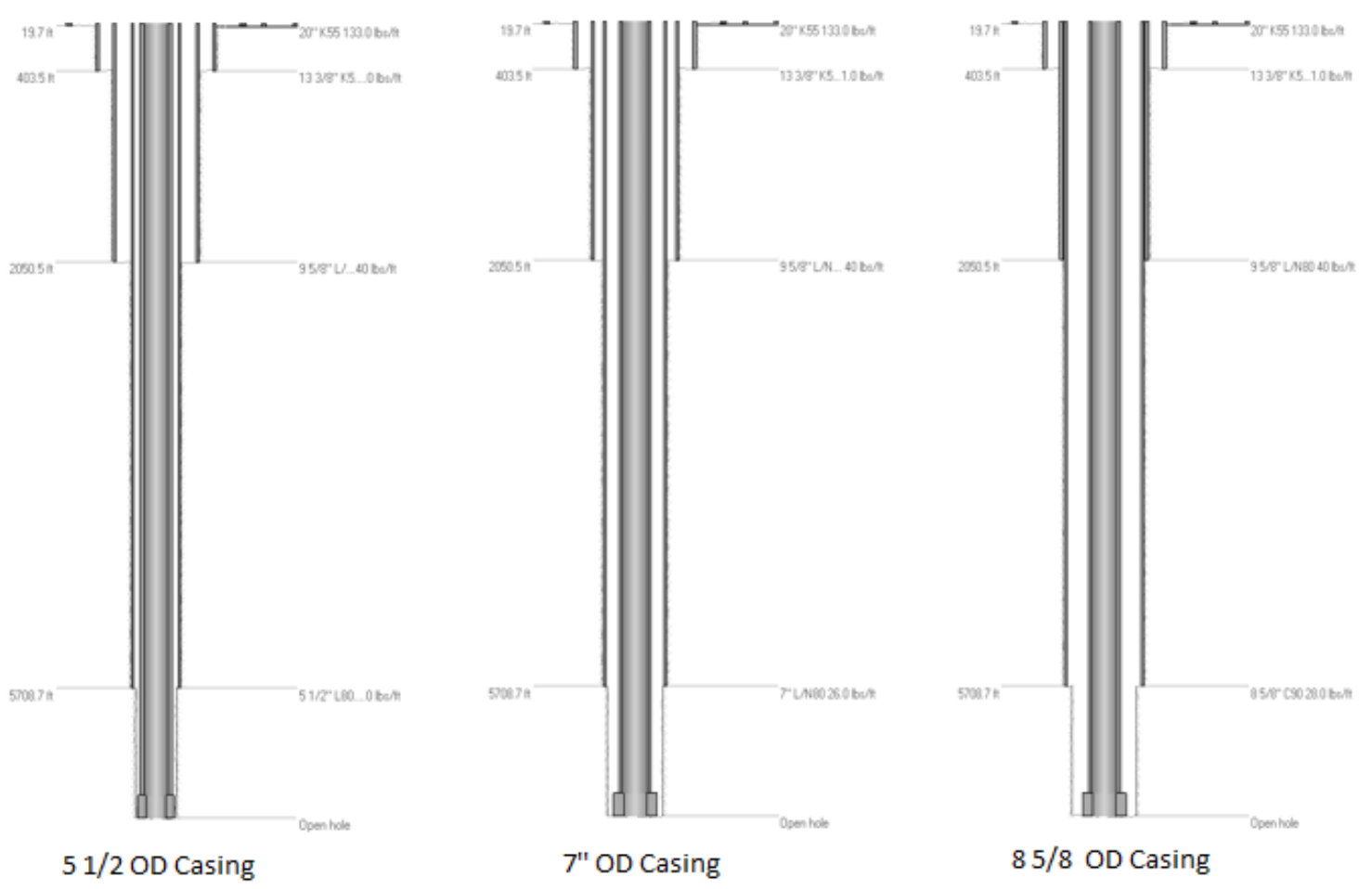

Figure 4 Vertical wellbore geometry

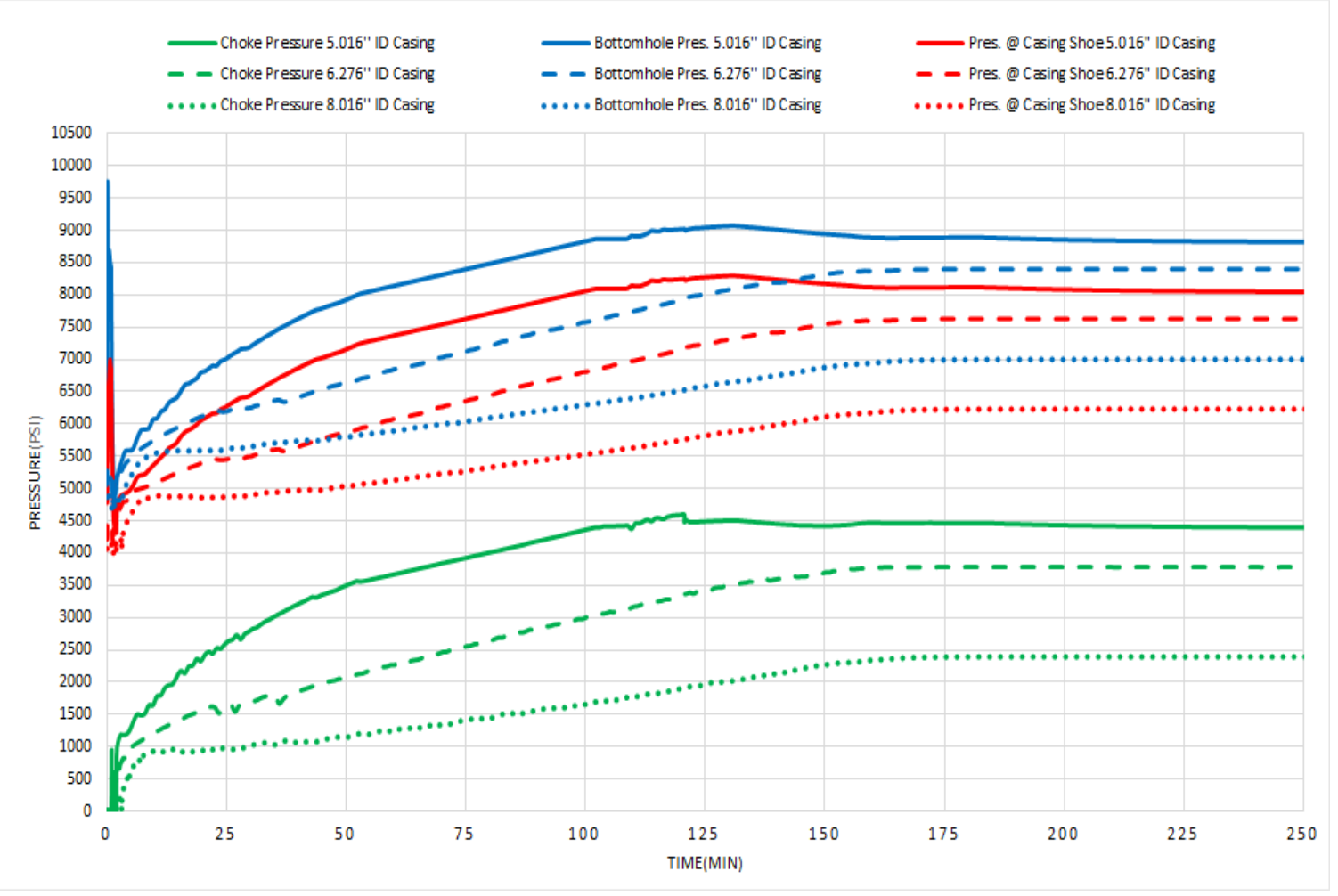

Figure 5 Effect of annular clearance on pressure variation in a vertical well with WBM. 


\subsection{Effect of Reservoir Pressure}

Several factors affect the severity of a kick. An important factor, for example, is the "permeability" of rock, which is its ability to allow fluid to move through the rock. Another factor affecting kick severity is the formation "porosity". Porosity measures the amount of space in the rock containing fluids. A rock with high permeability and high porosity with greater reservoir pressure has a high potential for a severe kick than a rock with low permeability and low porosity. For example, sandstone is considered to have greater kick potential than shale, because sandstone has greater permeability and porosity than shale.

Another factor affecting kick severity is the "pressure differential" involved. Pressure differential is the difference between the formation fluid pressure and the mud hydrostatic pressure. If the formation pressure is much greater than the hydrostatic pressure, a large negative differential pressure exists. If this negative differential pressure is coupled with high permeability and high porosity, a severe kick can occur.

The influence of reservoir pressure on annular wellbore pressures in a vertical well drilled with WBM is illustrated in Figure-6. The change in reservoir pressure had a remarkable impact on surface and downhole pressures with 13.35 ppg. WBM in the wellbore where reservoir pressures of 5500, 6500, and 7500 psi were considered. The bottom hole hydrostatic pressure was 4737 psi for each case. The higher reservoir pressure resulted in a larger influx size in the wellbore due to the pressure difference between bottom hole hydrostatic pressure and reservoir pressure even though the surface pit gain was maintained constant at 6.2 bbl. For example, pressure difference between reservoir pressure of $5500 \mathrm{psi}$ and bottom hole hydrostatic pressure of $763 \mathrm{psi}$ caused 5.9 bbl downhole influx. However, pressure difference between reservoir 
pressure of 7500 psi and bottom hole hydrostatic pressure of 2763 psi created $8.3 \mathrm{bbl}$ downhole influx in wellbore. Hence, the bigger difference between hydrostatic pressure and reservoir pressure created bigger size of kicks. The downhole total influx values were $5.9 \mathrm{bbl}, 6.8 \mathrm{bbl}$, and $8.3 \mathrm{bbl}$ with reservoir pressures of 5500, 6500, 7500 psi, respectively.

Reservoir pressures of 5500, 6500, and 7500 psi created 2657 psi, 3758 psi, and 5066 psi surface choke pressures and 7224, 8330, 9671 psi bottom hole pressures. The maximum surface choke pressure difference was 2409 psi for reservoir pressures of 5500 psi and 7500 psi. Also, the maximum bottomhole pressure difference observed was 2447 psi. This significant pressure increase may exceed casing burst pressure or fracture pressure at the shoe. It can be inferred that the bigger influx size creates higher annular wellbore pressures.

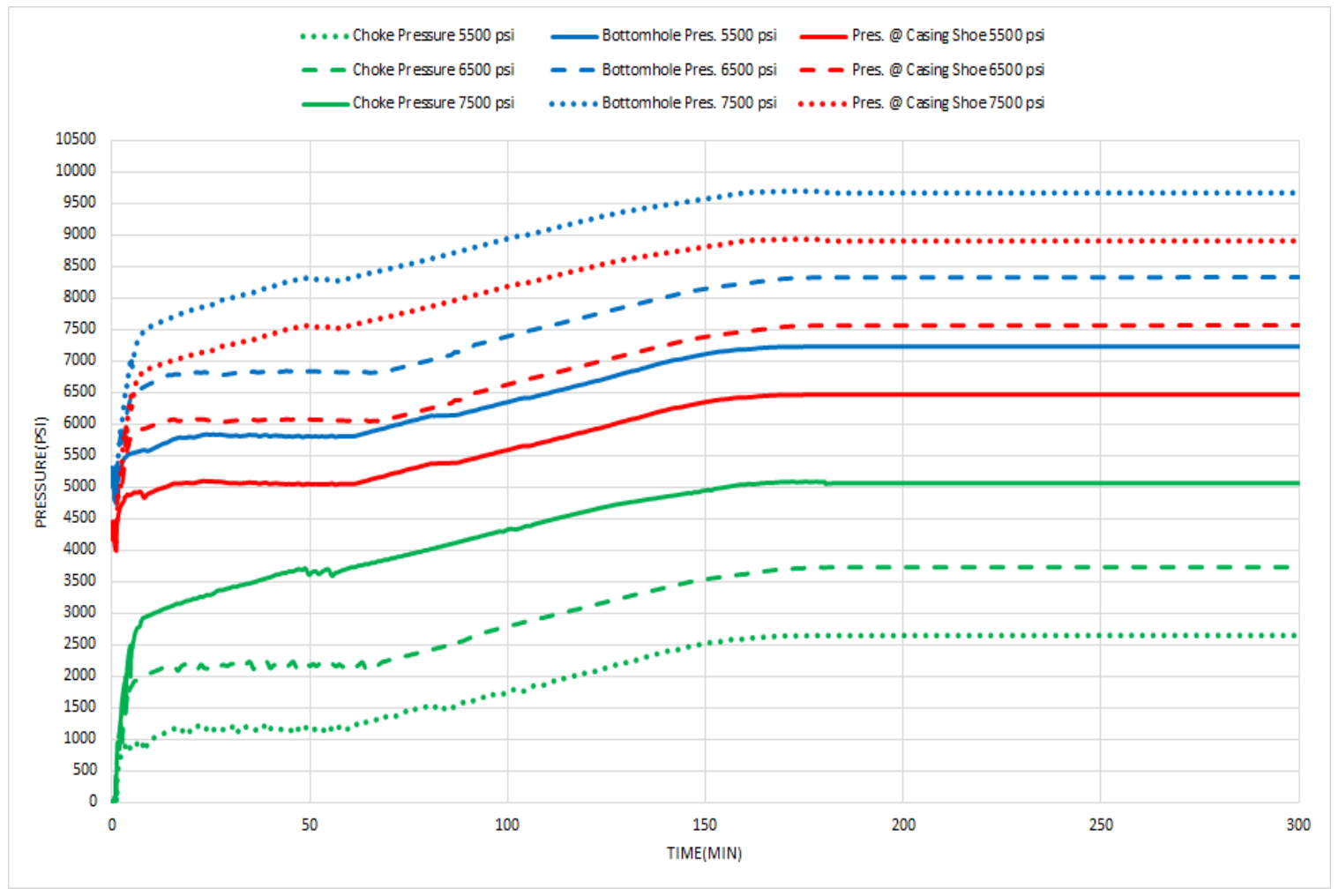

Figure 6 Variation of surface and bottomhole pressures for three different reservoir pressures in a vertical well with OBM.

The impact of reservoir pressure on annular gas solubility in OBM is illustrated in 
Figure-7. Three reservoir pressures values of 5500 psi, 6500 psi, and 7500 psi were evaluated with OBM. The most important difference with reservoir pressure was gas solubility in OBM compared to WBM. Gas is more soluble in OBM when pressure increases. Figure-7 presents dissolved gas as a function of depth at 5500 psi, 6500 psi, and 7500 psi reservoir pressures. Figure- 7 shows that the dissolved gas percentage at 7500 psi reservoir pressure was bigger than the percentage of dissolved gas at $6500 \mathrm{psi}$ and 5500 psi reservoir pressures. Pressure also had an impact on dissolution time at a given depth in the wellbore. Gas migrated until it completely dissolved in OBM at each case. Gas was not able to migrate further in the wellbore when pressure was higher because gas dissolves very quickly at higher pressures. For example, gas dissolved in 41 min. at $5434 \mathrm{ft}$. depth with $7500 \mathrm{psi}, 79 \mathrm{~min}$. at $5235 \mathrm{ft}$. depth with $6500 \mathrm{psi}$, and 120 min. at $5063 \mathrm{ft}$. depth with $5500 \mathrm{psi}$. It was obvious that the reservoir pressure had a great impact on gas solubility in OBM.

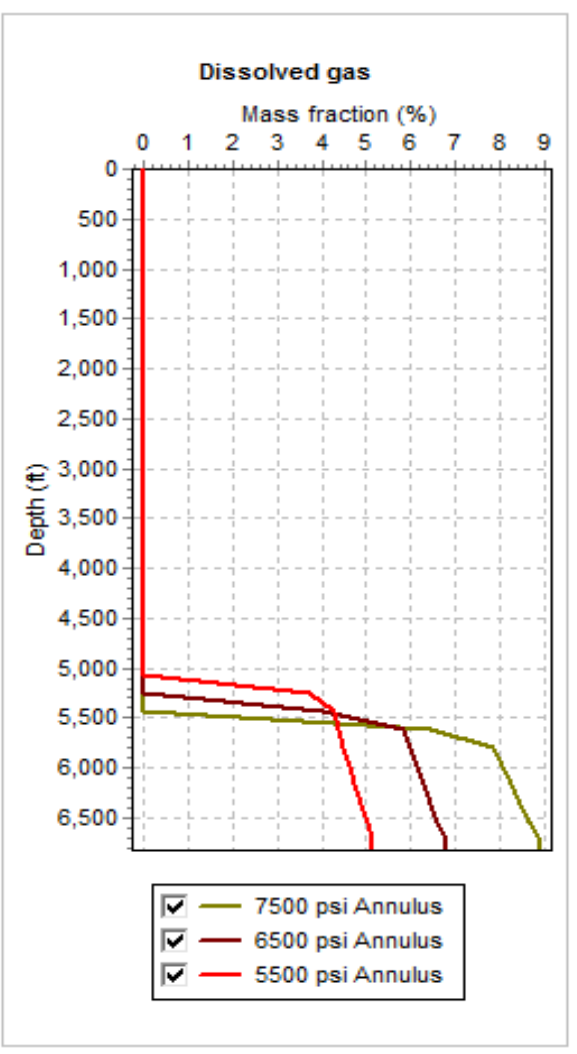

Figure 7 Effect of reservoir pressure on dissolved gas distribution in a wellbore. 
The influence of reservoir pressure on annular wellbore pressures in a vertical well drilled with OBM is illustrated in Figure-8. The results were similar to the wellbore with WBM. The higher reservoir pressure generated higher wellbore annular pressures. For example, 7500 psi reservoir pressure created 1000 psi additional pressure at the surface than 6500 psi reservoir pressure and 1997 psi additional pressure than 5500 psi reservoir pressure. Reservoir pressure also had a significant impact on pressure at casing shoe. Reservoir pressures of 5500 psi, 6500 psi, and 7500 psi created 4874 psi, $5904 \mathrm{psi}$, and 6920 psi pressure at the casing shoe, respectively. The higher pressure at choke can exceed the maximum allowable casing shoe pressure and it can cause failure at casing.

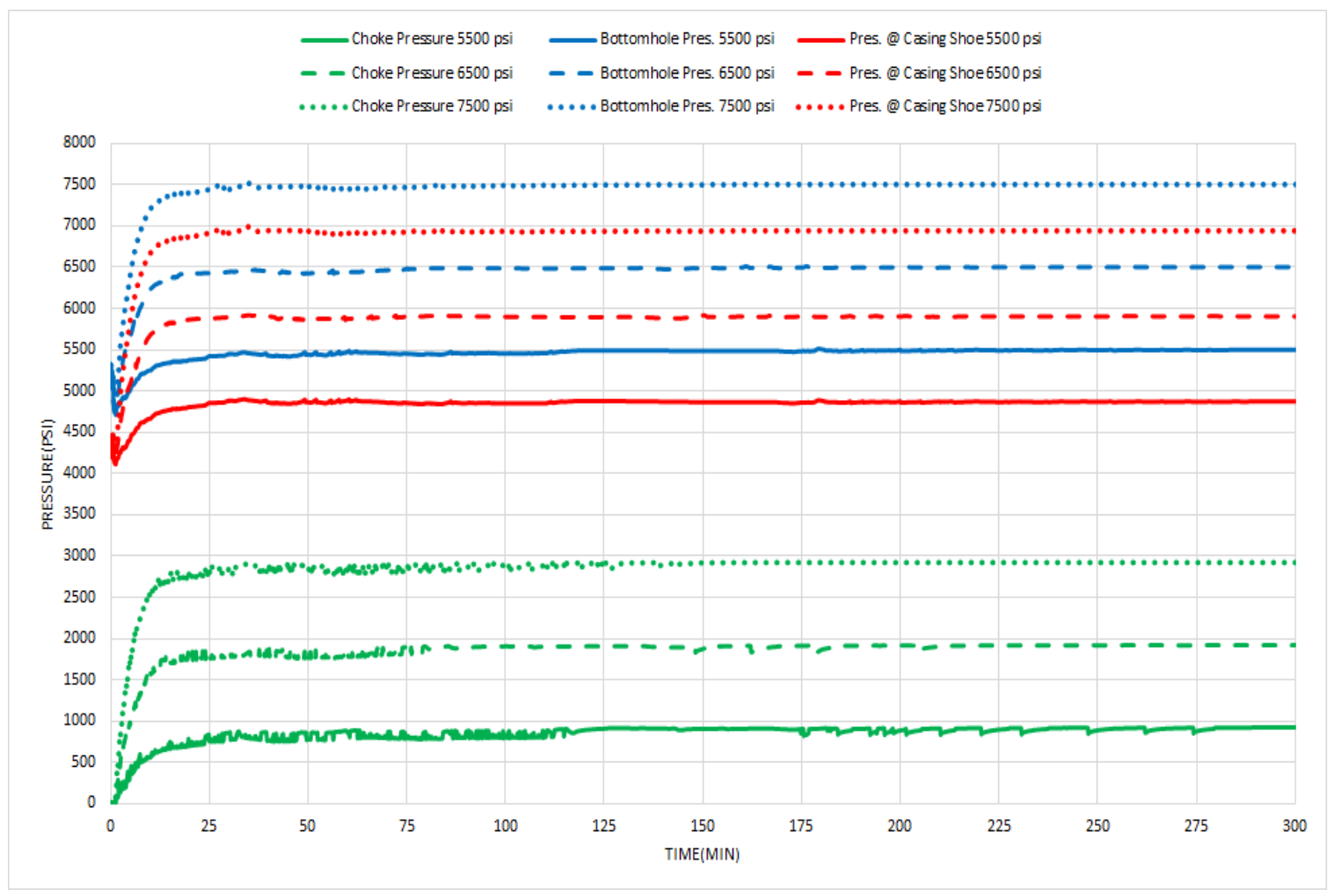

Figure 8 Variation of surface and bottom hole pressures for three different reservoir pressures in a vertical well with WBM.

Another result concluded from Figure 8 was the change in gas dissolution time with the different reservoir pressures. The choke pressure curves in Figure 8 shows that 
fluctuations stop at different times. The fluctuations stop due to complete dissolving of gas in the OBM. For example, gas dissolution took around $140 \mathrm{~min}$. at the reservoir pressure of $7500 \mathrm{psi}$ and $275 \mathrm{~min}$. at the reservoir pressure of 5500 . Therefore, it can be inferred that gas dissolves quicker at the higher reservoir pressure because pressure increases the degree of the gas solubility in OBM.

\subsection{Effect of Drilling Fluid Type and Density}

Water-based muds (WBMs) and oil-based muds (OBMs) are commonly used in drilling, although there is an increasing trend towards WBMs and pseudo OBMs for environmental reasons. WBMs are considered to provide an opportunity to isolate the effects of gas solubility on kick expansion. When a reservoir fluid mixes with a WBM, there is very little mutual solubility between the water and the hydrocarbon phases. The expansion of the kick may be treated as independent of the mud. OBM consists of a hydrocarbon-based oil, brine, and various solids such as barite, sand, and clay. Methane and condensates are miscible with the base oil at high pressures, and the solubility of the reservoir fluid in the oil element is composition dependent.

Figure- 9 shows the influence of mud weight change on wellbore pressures and gas rise velocity. This included the use of $11.20 \mathrm{ppg}, 13.35 \mathrm{ppg}$ and $15.52 \mathrm{ppg}$ mud weights for OBM in a vertical well. The surface pit gain was maintained at the level of 6.2 bbls for each case. However, downhole gas influx volume was different since the hydrostatic pressure was different for each mud weight. 


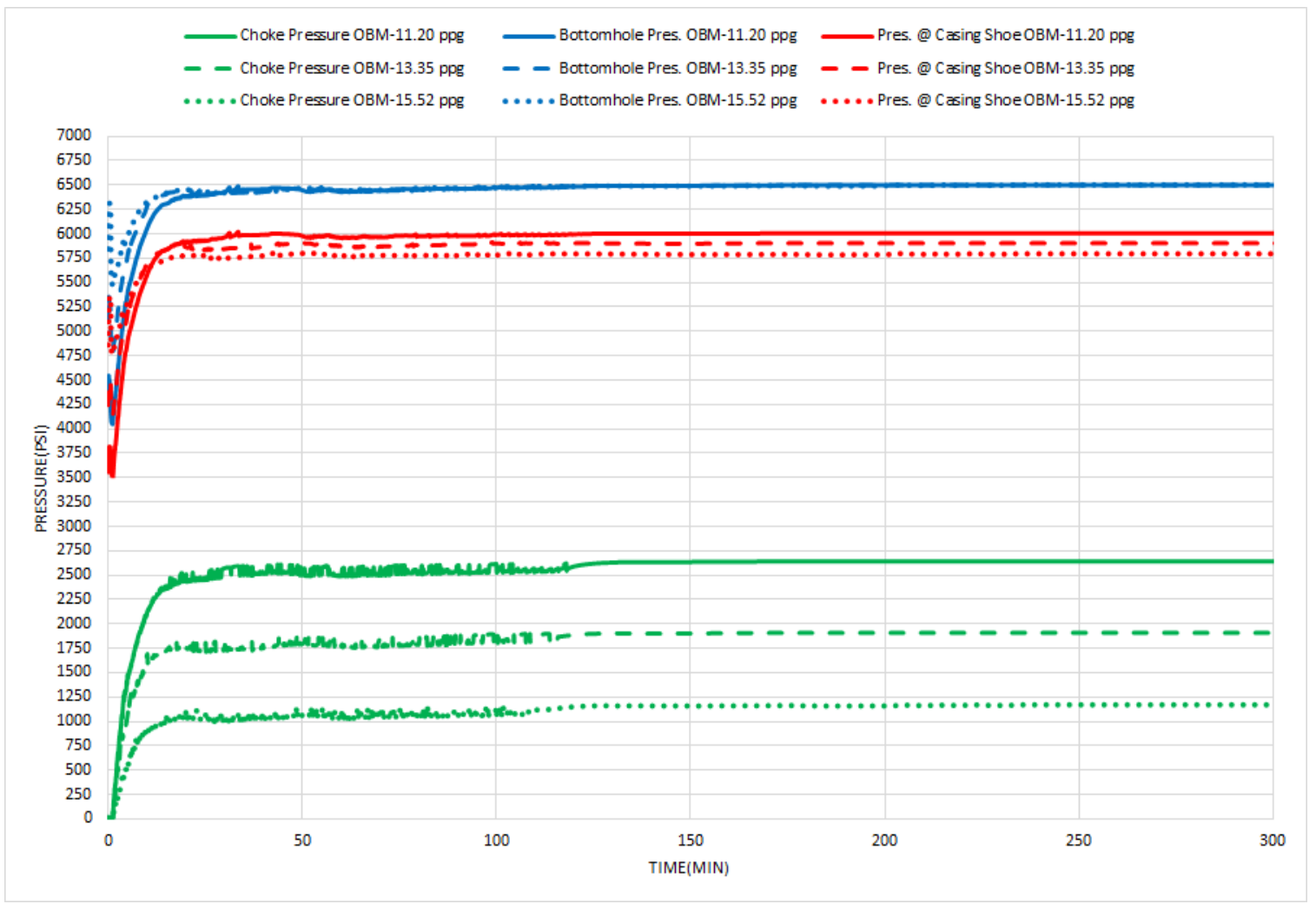

Figure 9 Variation of pressures with time in a vertical well for Oil Based Mud Density.

The difference between hydrostatic pressure and reservoir pressure has an influence on kick size as mentioned in the earlier sections. Thus, 6500 psi of reservoir pressure was maintained in each case. However, 11.20 ppg, 13.35 ppg and 15.52 ppg mud densities created 3974 psi, 4737 psi, 5507 psi hydrostatic pressures at the bottom hole. The higher mud weight caused the higher hydrostatic pressure at the bottom hole, which decreases the differential pressure between formation and bottomhole. For that reason, a smaller size of gas kick enters the wellbore when higher drilling fluid density used. For example, $14.4 \mathrm{bbl}, 12.5 \mathrm{bbl}$, and $10.8 \mathrm{bbl}$ kick sizes were recorded with 11.20 ppg, 13.35 ppg and 15.52 ppg mud densities. Pressure stabilized after 115 minutes when gas influxes were completely dissolved. Choke pressure was greater for the lower mud weight since bigger volume of kick enters the wellbore. For $11.20 \mathrm{ppg}$ OBM, the maximum choke pressure and gas rise velocity were 2650 psi and $12.7 \mathrm{ft} / \mathrm{min}$, 
respectively. Figure-10 shows wellbore pressure variation at different mud weights in WBM. Since gas solubility in WBM was insignificant, gas kick migrated to the top of the well. For the $11.20 \mathrm{ppg}$ WBM, the maximum choke pressure and gas rise velocity were $4575 \mathrm{psi}$ and $49.2 \mathrm{ft} / \mathrm{min}$.

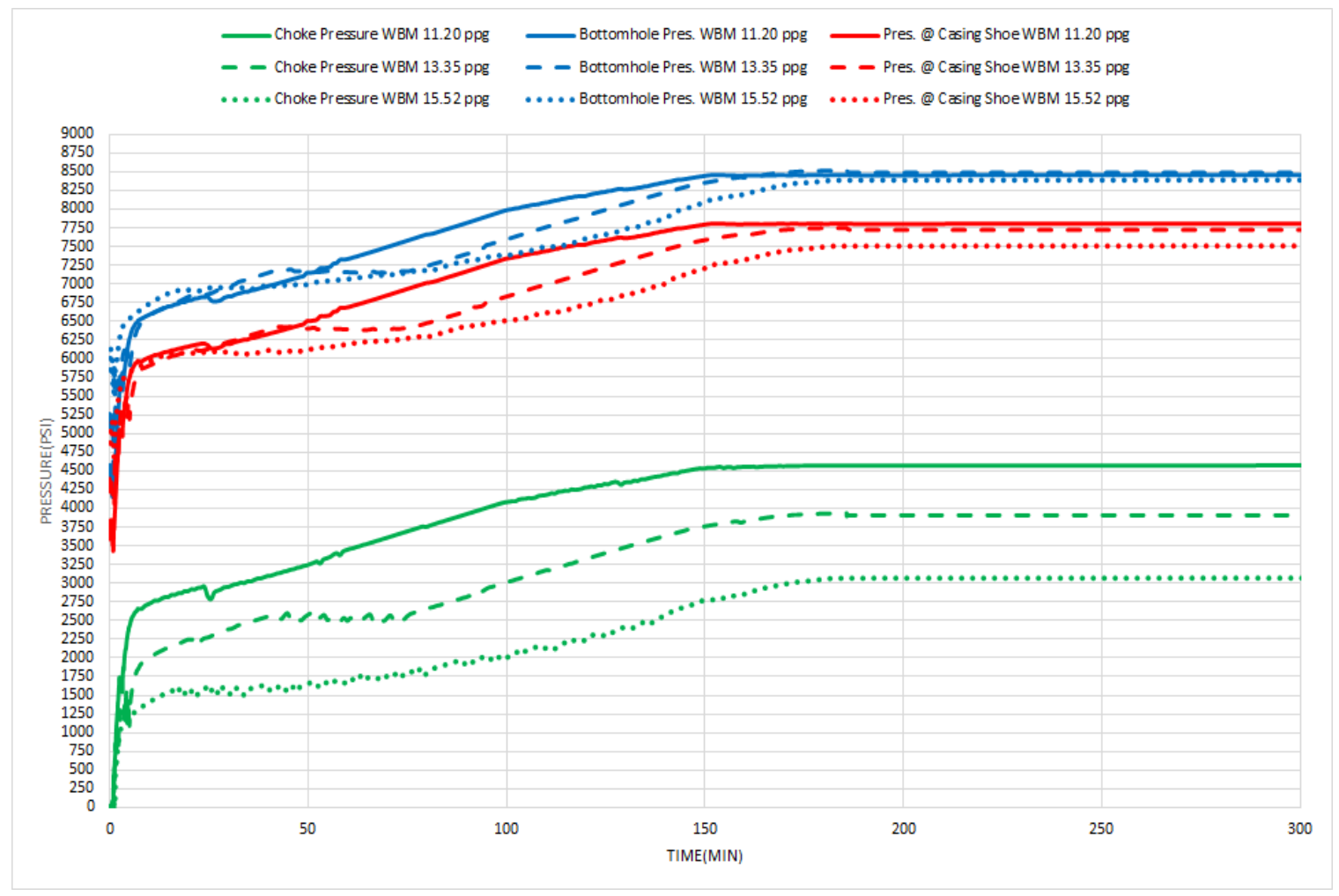

Figure 10 Variation of pressures with time in a vertical well for Water Based Mud Density.

Figure-11 compares pressure variations for WBM with OBM when $11.20 \mathrm{ppg}$ mus was used. It was obvious that pressure variation and gas rise velocity were much higher in WBM than in OBM. For instance, gas migrated approximately 3.8 times faster in WBM. Also, the observed choke pressure was 1925 psi greater for 11.20 ppg of WBM than in OBM. 


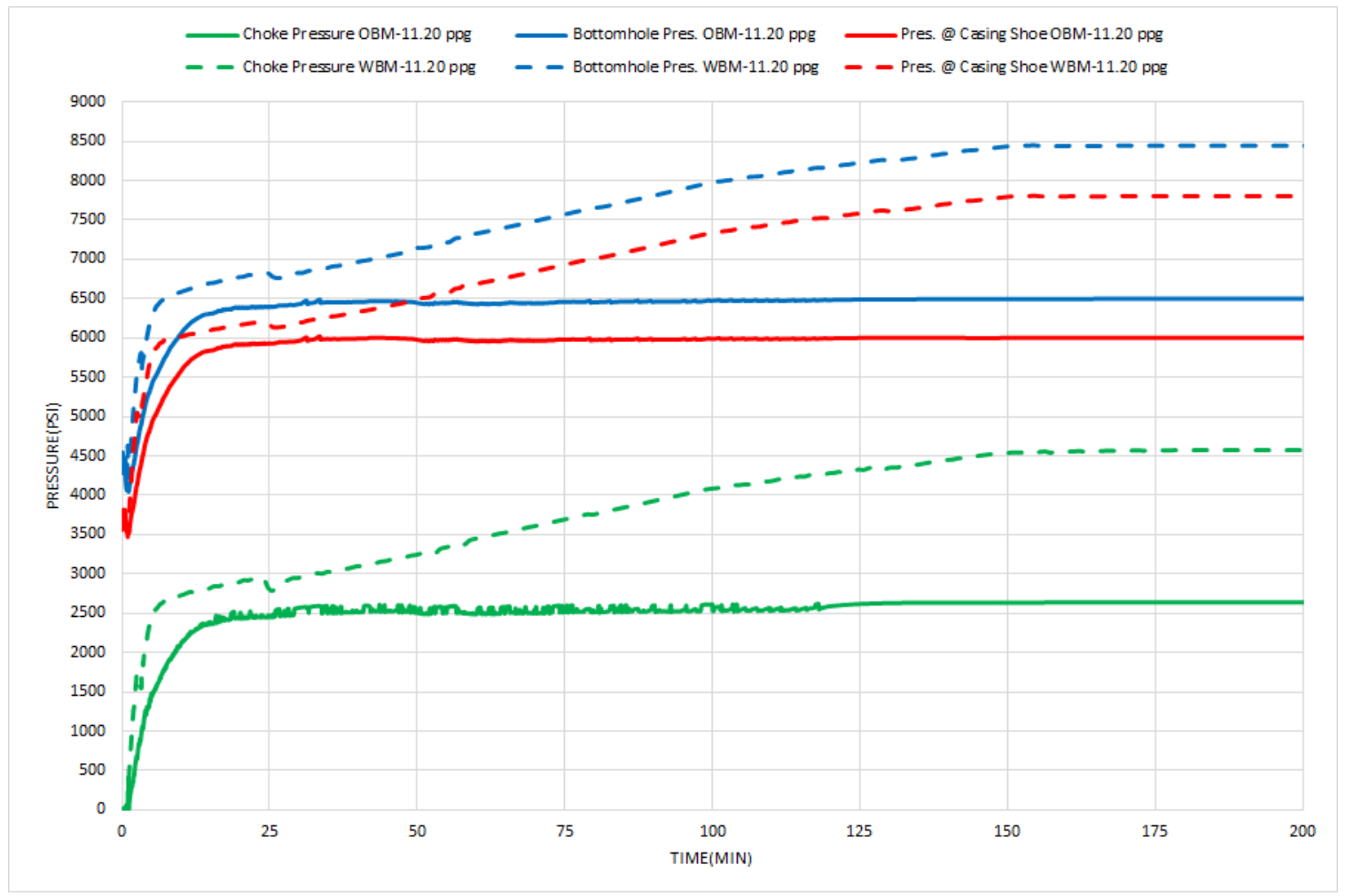

Figure 11 Variation of pressures with time in a vertical well with OBM and WBM.

\subsection{Effect of Wellbore Geometry}

The results of pressure variation are presented in Figure-12 for three different wellbore trajectories when WBM was used. Vertical and directional wellbores experienced similar pressure increases whereas the pressure increase for the horizontal well was delayed for a duration equal to the gas travel time in the horizontal section. For the horizontal case, the delay time was approximately 200 minutes. The pressure increase for the horizontal well occurred when the gas kick reached the end of the kick of point (KOP). Among the three wellbore trajectories, horizontal wellbore experienced the lowest surface and bottomhole pressures. Gas rise velocities slightly changed in each wellbore trajectories. The highest gas rise velocity was seen in vertical well, which was $49.8 \mathrm{ft} / \mathrm{min}$, and the lowest velocity was seen in horizontal well as $44.4 \mathrm{ft} / \mathrm{min}$. 


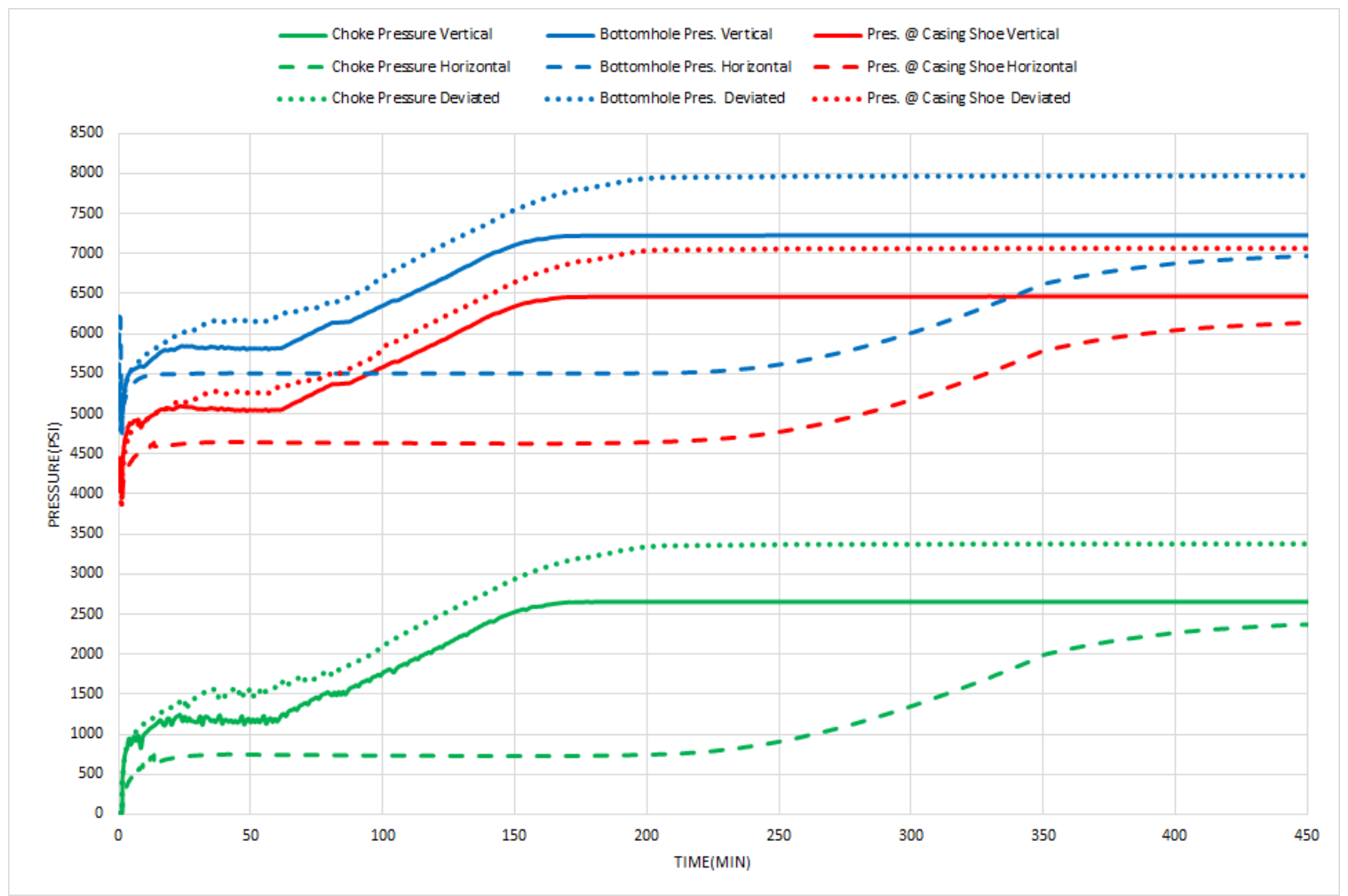

Figure 12 Variation of pressures with time in a well with WBM for three different wellbore trajectories.

\subsection{Effect of Deviation Angle}

Pressure build up was examined for six different deviation angles for a well with WBM. These deviation angles were $0^{\circ}, 30^{\circ}, 45^{\circ}, 60^{\circ}$, and $75^{\circ}$. Pressure builds up changed with the deviation angle. From zero to $30^{\circ}$ angle deviations, pressure builds up with gas kick entering the wellbore. After that pressure stabilized until gas reached to the kick of point. Once gas kick passed the kick off point, pressure builds up again until it reached the surface. On the contrary, from $45^{\circ}-60^{\circ}$ angle, pressure does not stabilize until the gas kick reached to the kick off point. Pressure builds up started with gas kick entering the well until it arrived to the top of the well. Pressures observed at the choke for $0^{\circ}$ and $30^{\circ}$ are $2657 \mathrm{psi}$ and $2989 \mathrm{psi}$, respectively. The maximum choke pressure of 3630 psi was seen at $60^{\circ}$ angle. The second highest pressure of 3520 psi was seen at $45^{\circ}$ angle. After $60^{\circ}$ angle, pressure did not increase as much as it was seen at $0^{\circ}, 30^{\circ}$, 
$45^{\circ}$, and $60^{\circ}$. For instance, pressure seen at choke with the $75^{\circ}$ deviation angle was 2633 psi, which was the lowest choke pressure among those six well deviation angles, and pressure build up pattern changes with $75^{\circ}$ angle.

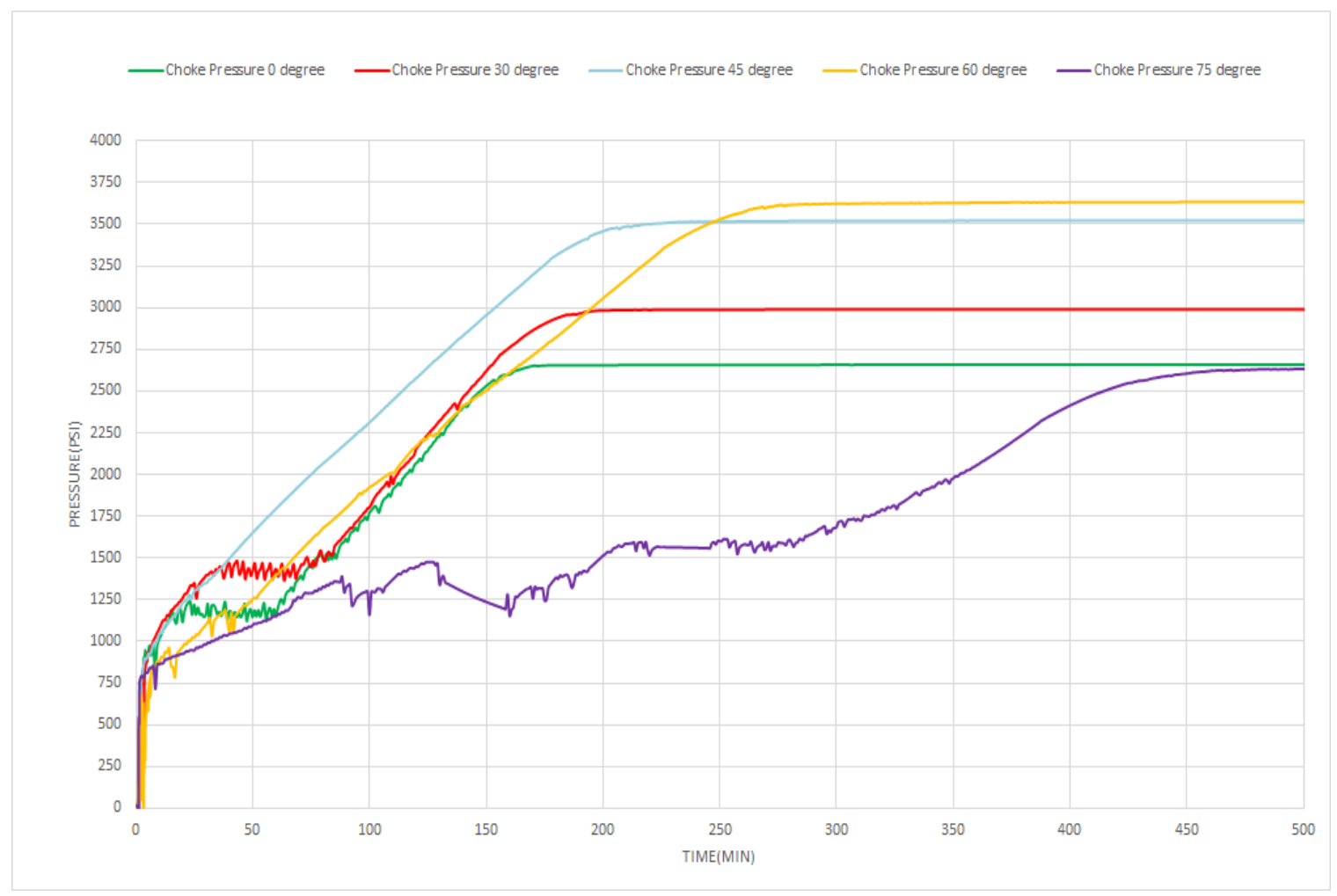

Figure 13 Variation of choke pressures with time in a well with WBM for different wellbore deviation angles.

\subsection{Effect of Reservoir Temperature}

As discussed earlier, temperature has an impact on gas solubility in oil based muds. Figure-14 represents the change of methane solubility at different temperatures (Thomas et al., 1984). It is clear that an increase in temperature decrease gas solubility in OBM. The impact of reservoir temperature on wellbore pressures was investigated and the results are shown in Figure-15. Three different reservoir temperatures of $200^{\circ} \mathrm{F}$, $300^{\circ} \mathrm{F}, 400^{\circ} \mathrm{F}$ were used for a vertical well with OBM. Bottom-hole and casing shoe had very similar values and showed identical behavior for all three reservoir temperatures. 
Gas completely dissolved in OBM for each case. One of the differences observed was the change in kick volume at the downhole although the pit gains were the same. As given in the ideal gas law, $\mathrm{PV}=\mathrm{nRT}$, volume increases as the temperature increases.

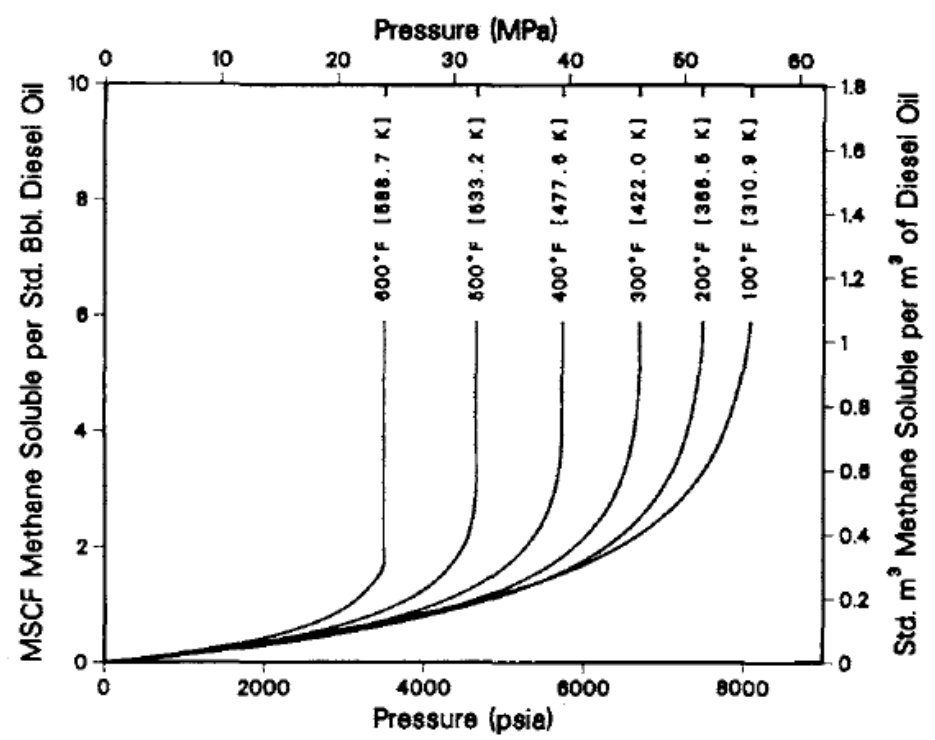

Figure 14 Methane solubility in diesel fuel (Thomas et al. 1984).

For example, the kick observed for $200^{\circ} \mathrm{F}$ reservoir temperature at the downhole was $12.7 \mathrm{bbl}$, for the $300^{\circ} \mathrm{F}$ reservoir temperature, the kick was $22.3 \mathrm{bbl}$ at the downhole. The second difference was the change in choke pressure. An increase in the temperature decreased the degree of gas solubility. At the high temperature, gas dissolution time shortens when it is compared to low temperatures. This impacts the dissolution depth of the kick. The gas kick climbs up in the wellbore when the temperature is higher in the annulus. Therefore, it creates more pressure at the surface. The choke pressures were 926, 1104, and 1192 psi for the reservoir temperatures of $200^{\circ} \mathrm{F}, 300^{\circ} \mathrm{F}$, and $400^{\circ} \mathrm{F}$, respectively. 


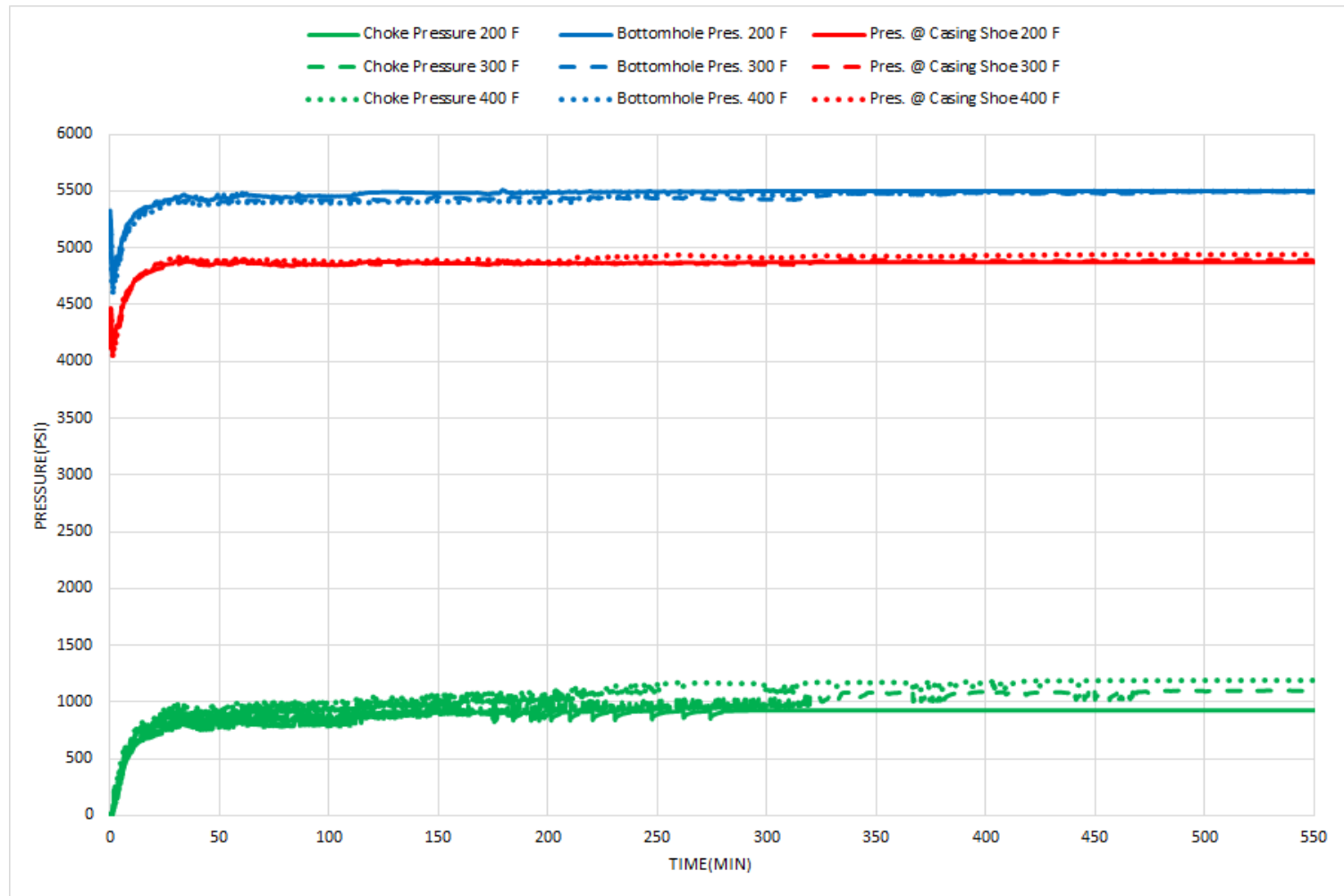

Figure 15 Variation of pressures with time in a well with OBM for three different reservoir temperatures.

\subsection{Effect of Water/Oil Ratio}

The ratio of oil to water percentage in the drilling fluid is defined as the Oil/Water Ratio (OWR). The change of OWR can affect the degree of gas solubility in OBM. The more oil in drilling fluid means the more gas solubility in OBM. In this study, an OBM with $13.35 \mathrm{ppg}$ mud weight was simulated with three different OWR. These were 90/10, $70 / 30$ and $50 / 50$ oil/water ratios. The results of the runs are shown in Figure-16. Free gas influx started dissolving immediately at highest OWR of 90/10. However, while migrating, gas influx dissolved completely in all three OWRs. 


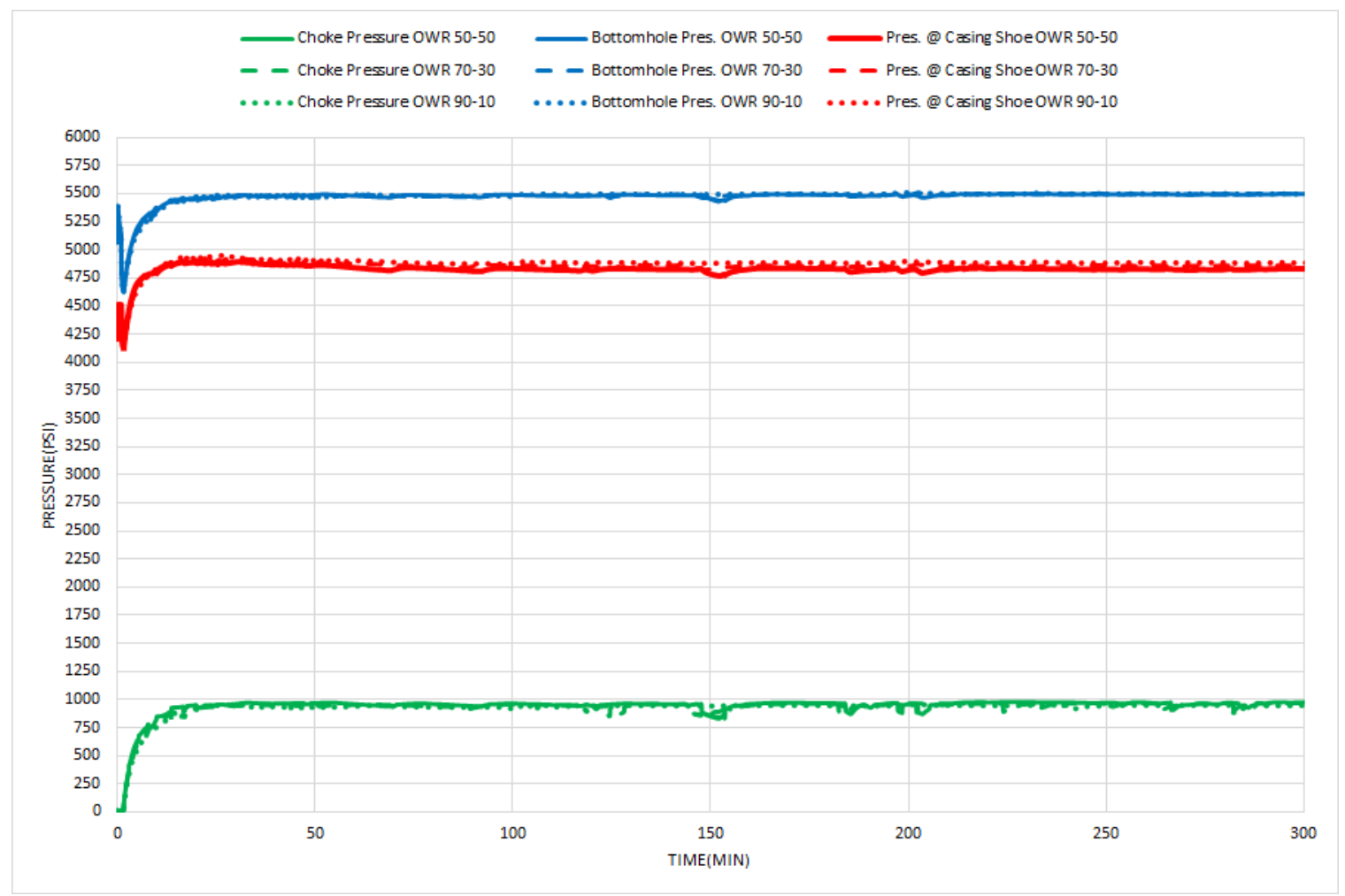

Figure 16 Variation of pressure with time in a deviated well for three different Oil/Water ratios.

Although pressure variations were insignificant for the different OWR values, gas influx dissolved at different well depths. The gas reached upper parts of the well when the OWR of mud was lowest at $50 / 50$ because an increase of water phase in the drilling fluid allowed more free gas to migrate to the upper part of the well. For instance, dissolution depths in the wellbore were $3600 \mathrm{ft}$ for 50/50 OWR, $4500 \mathrm{ft}$ for 70/30 OWR, and $4900 \mathrm{ft}$ for $90 / 10$ OWR (Figure-17). 


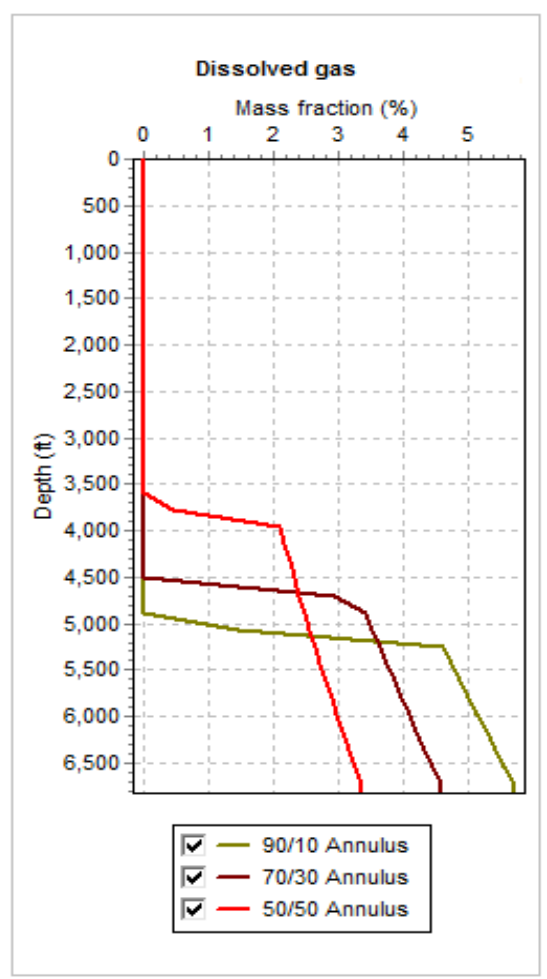

Figure 17 Dissolved gas depth and dissolved gas mass fraction for three different oil/water ratios.

Figure-18 shows the gas solubility changes with the pressure studied by Monteinero et al. (2005). The results found in this case supports the study of Monteinero et al. Clearly, higher the OWR, higher was the degree of gas solubility in the OBM.

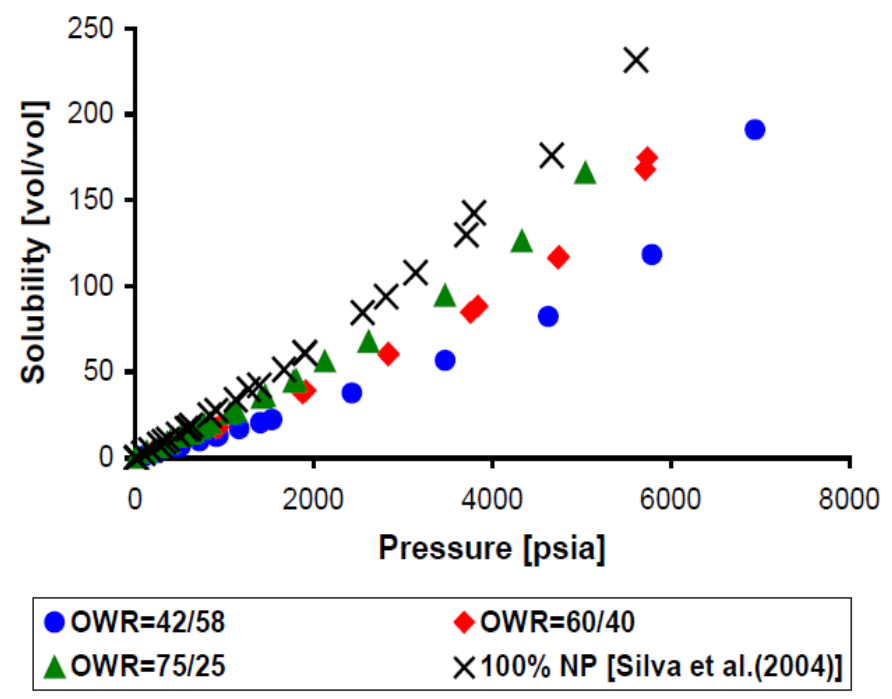

Figure 18 Effect of oil/water ratio on the methane solubility in an emulsion (Monteiro. 2005). 


\subsection{Effect of Mud Yield Point and Mud Plastic Viscosity}

The impacts of mud yield point (YP) and mud plastic viscosity (PV) in WBM were investigated using Bingham plastic model. The Bingham plastic model was selected as the rheological model since it has yield strength of drilling fluid, which is above zero. By definition, YP of the drilling mud is used to evaluate cutting carrying capacity of the mud. $13.35 \mathrm{ppg}$ water based mud with $5,10,15 \mathrm{lb} / \mathrm{ft}^{2}$ values were used because the possible YP values were within a range for $13.35 \mathrm{ppg}$ mud as shown in Appendix A-3. Investigation of the impact of YP on wellbore annular pressures and gas rise velocity results are shown in Figure-19.

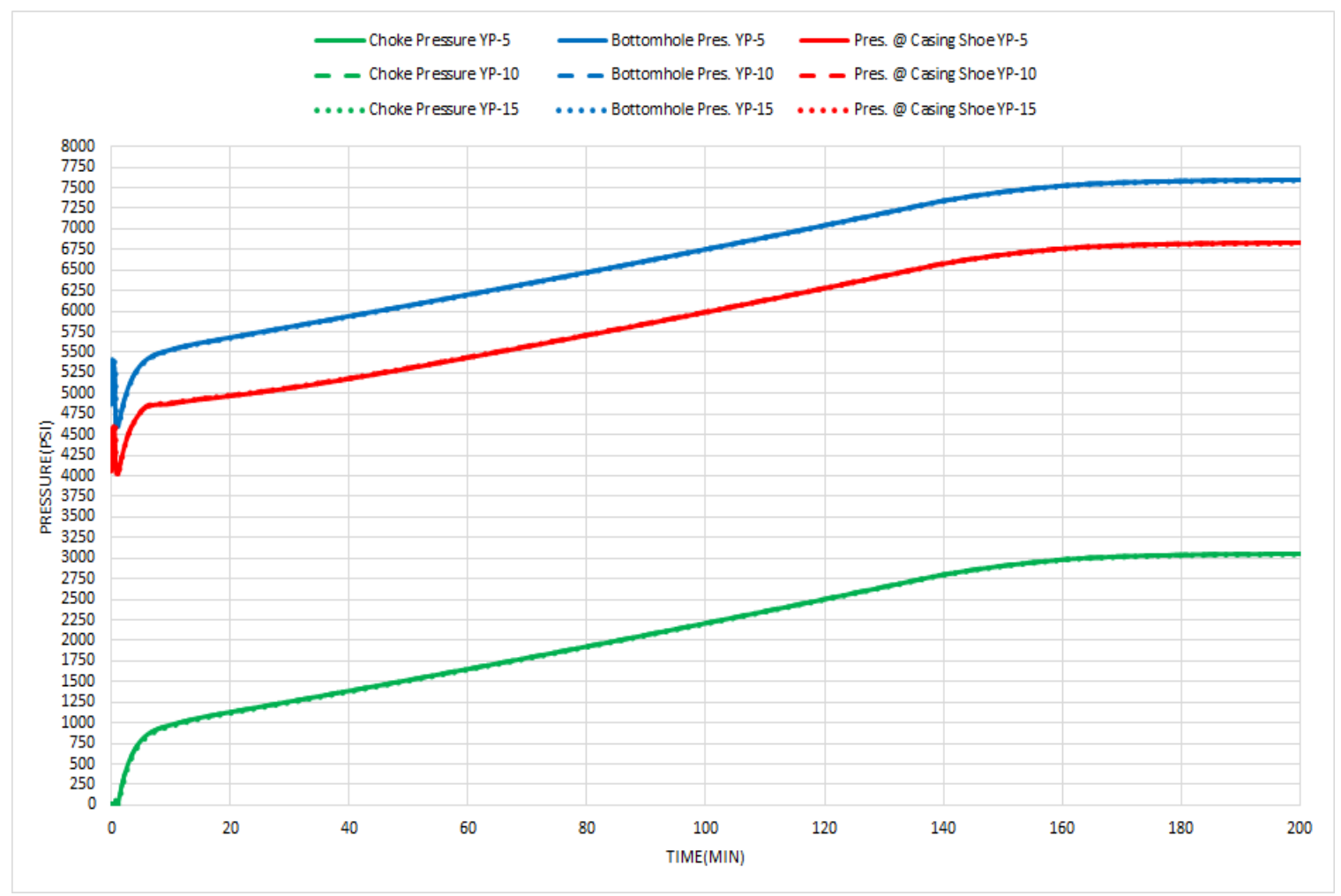

Figure 19 Variation of pressure with time in a deviated well for three different mud yield points.

PV indicates the solid content of the drilling fluid and system friction losses. 12 cp., $19 \mathrm{cp}$., and $26 \mathrm{cp}$. PV values for 13.35 ppg WBM are examined while keeping YP 
constant. The possible range of PV values for 13.35 ppg mud is shown in Appendix A-3 section. The results are shown in Figure-19. As it is seen from Figure-19 and Figure-20, PV and YP have an insignificant impact on wellbore pressures and gas rise velocity since in a closed wellbore there is no circulation and the drilling fluid is in a static condition.

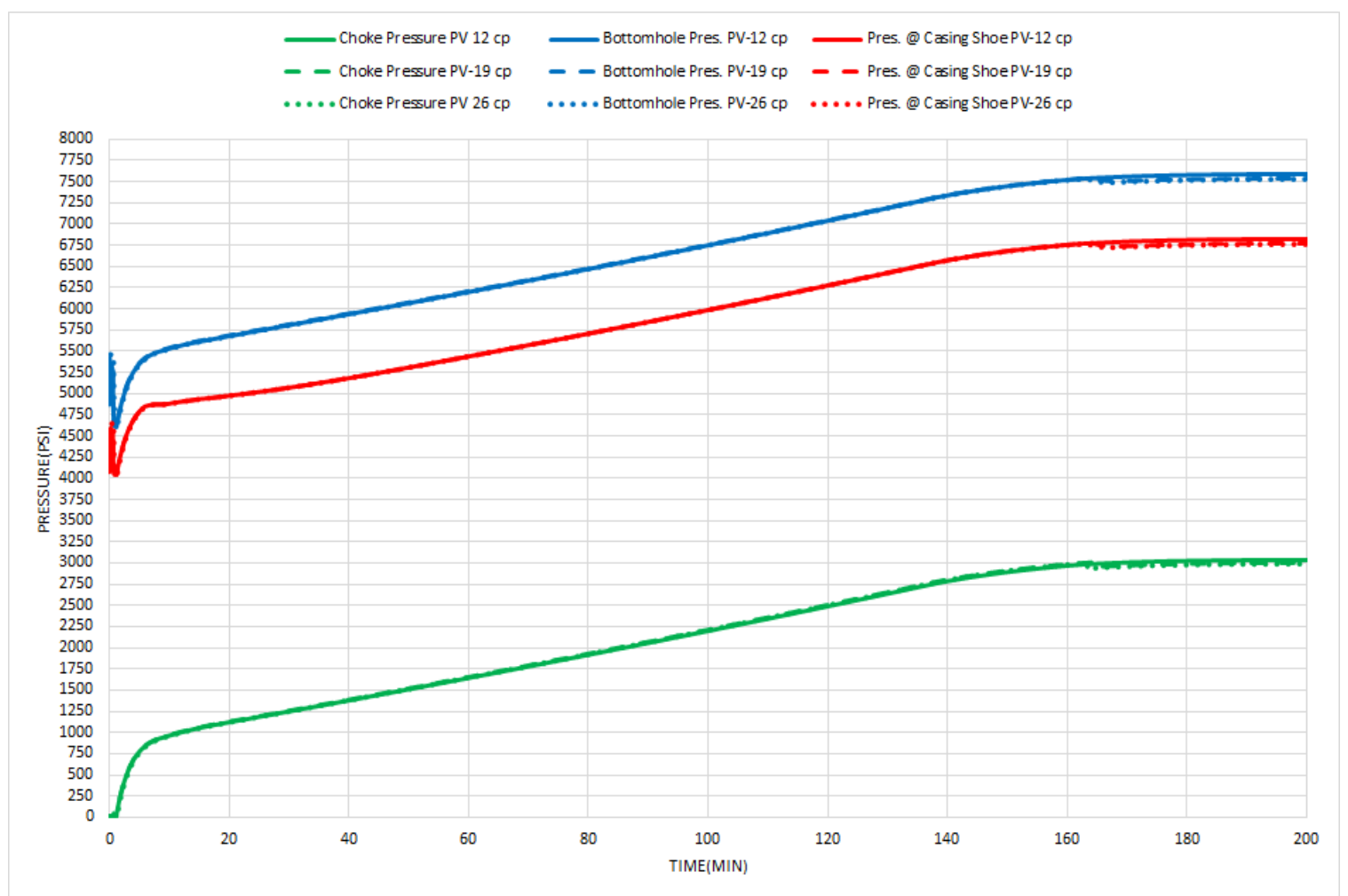

Figure 20 Variation of pressure with time in a deviated well for three different mud plastic viscosities.

The results are summarized and shown in Figure 21 for pressure variations conducted with oil-based mud. The green bars indicate choke pressures, the blue bars show the bottom hole pressures, and the red bars show the pressures at the casing shoe in psi units. The reservoir pressure had more impact on surface and wellbore pressures among the cases considered in this study. The higher formation pressures created bigger volume of kick and generated higher surface and wellbore pressures. The 
highest surface pressure was observed as 2923 psi, and 7500 psi was the highest bottom hole pressure for the case study for the impact of reservoir pressure. The bottom hole pressures were same or very close to formation pressure due to the kick gas solubility. The kick size had the second most influence on the surface and wellbore pressure.

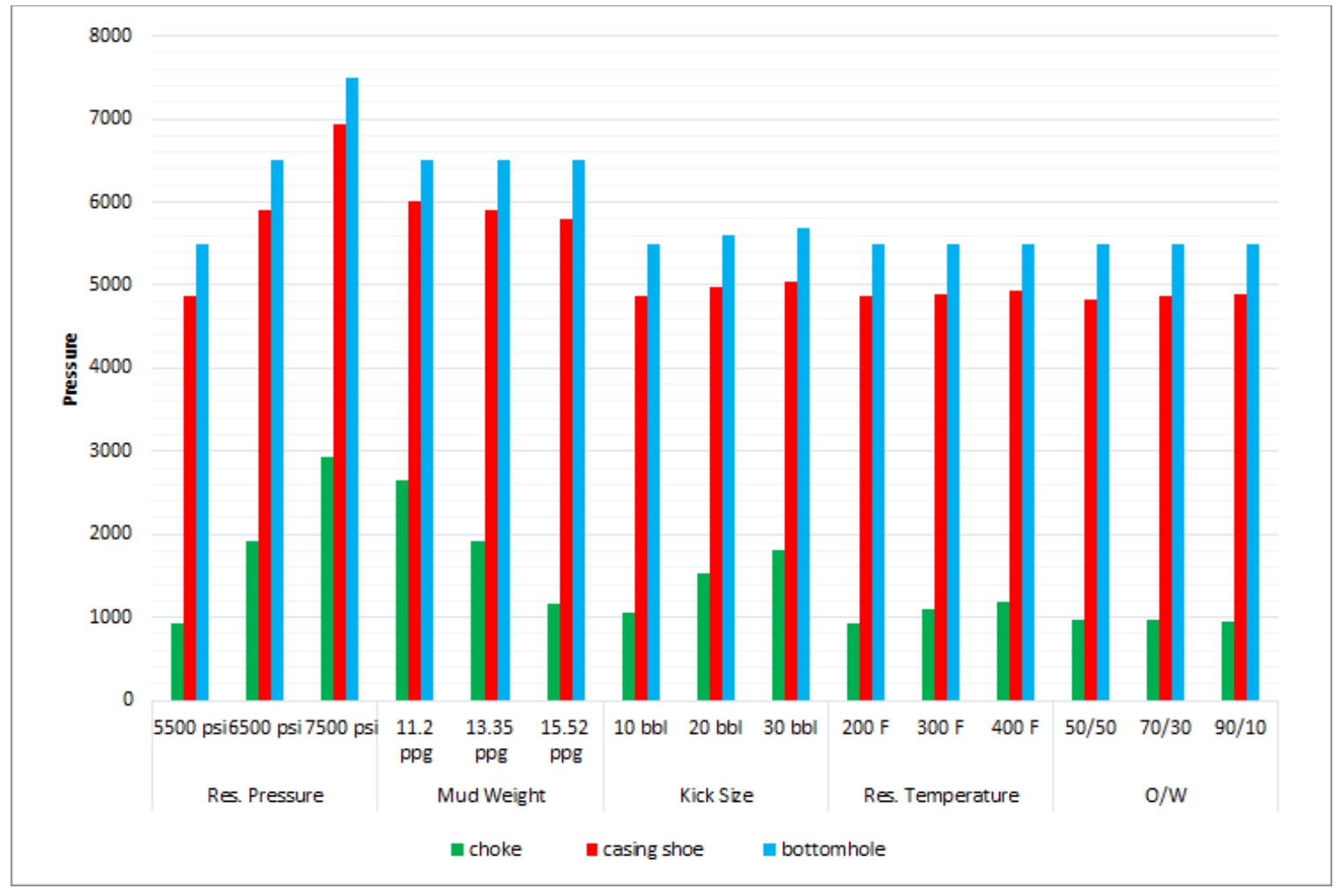

Figure 21 Summary of pressure variations in $O B M$.

Figure 22 shows the summary of pressure variations for water-based muds. The highest surface and wellbore pressures were observed for 7500 psi reservoir pressure. The bottom hole pressure was 9671 psi and choke pressure was 5066 psi. When these pressures are compared to pressures observed in OBM, it is concluded that surface and bottom hole pressures were higher in WBM then OBM as a result of the gas kick reaching surface without dissolving in WBM. Another result determined from figure 22 was the classification of cases with controllable and uncontrollable parameters. 
Reservoir pressure case had the biggest impact on surface and wellbore pressures as an uncontrollable parameter, and wellbore size case with the smaller annular area had the biggest influence on surface and wellbore pressures as a controllable parameter.

The highest bottom hole and choke pressures were monitored as 8811 psi and 4386 psi for cases involving wellbore size changes.

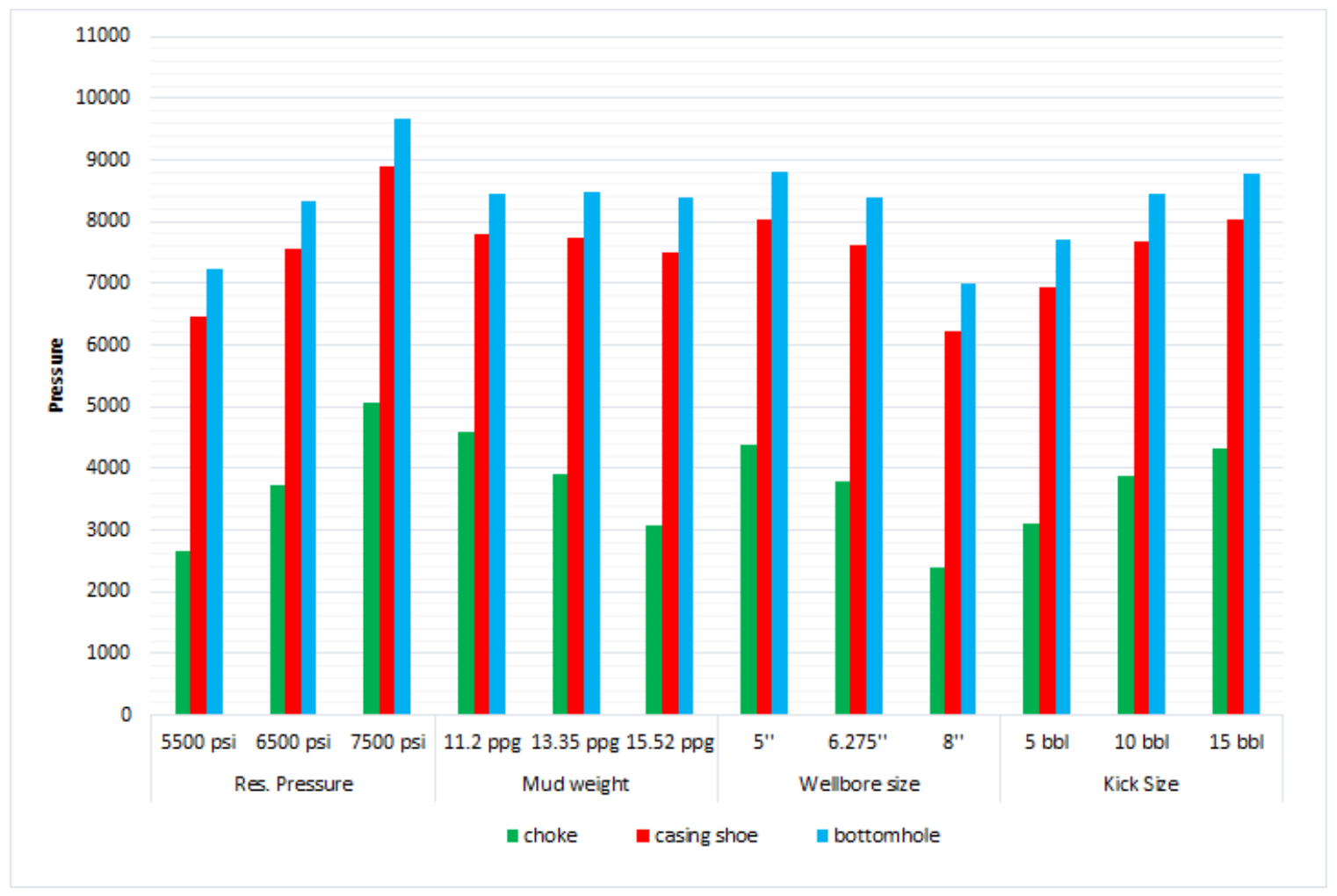

Figure 22 Summary of pressure variations in WBM

The results for average gas rise velocities are shown in Figure 22. The average gas rise velocity was calculated according to migration interval and arrival time. For example, in the water based mud arrival location was the surface since free gas reached the surface for all cases. However, in OBM, the arrival depth location was considered at a point where the free gas completely dissolved. If the gas was not completely dissolved, the arrival depth location was considered as surface because gas migrated to the surface. After the calculations for each case, the highest gas rise velocity was observed 
when the wellbore had the smaller annular area (5.016" ID casing), which was 82.2 $\mathrm{ft} / \mathrm{min}$. It was clear that the annular area had the greatest impact on gas rise velocity. It was also seen that gas was rising faster in WBM than OBM. The highest gas rise velocity in OBM was still lower than the lowest gas rise velocity in WBM.

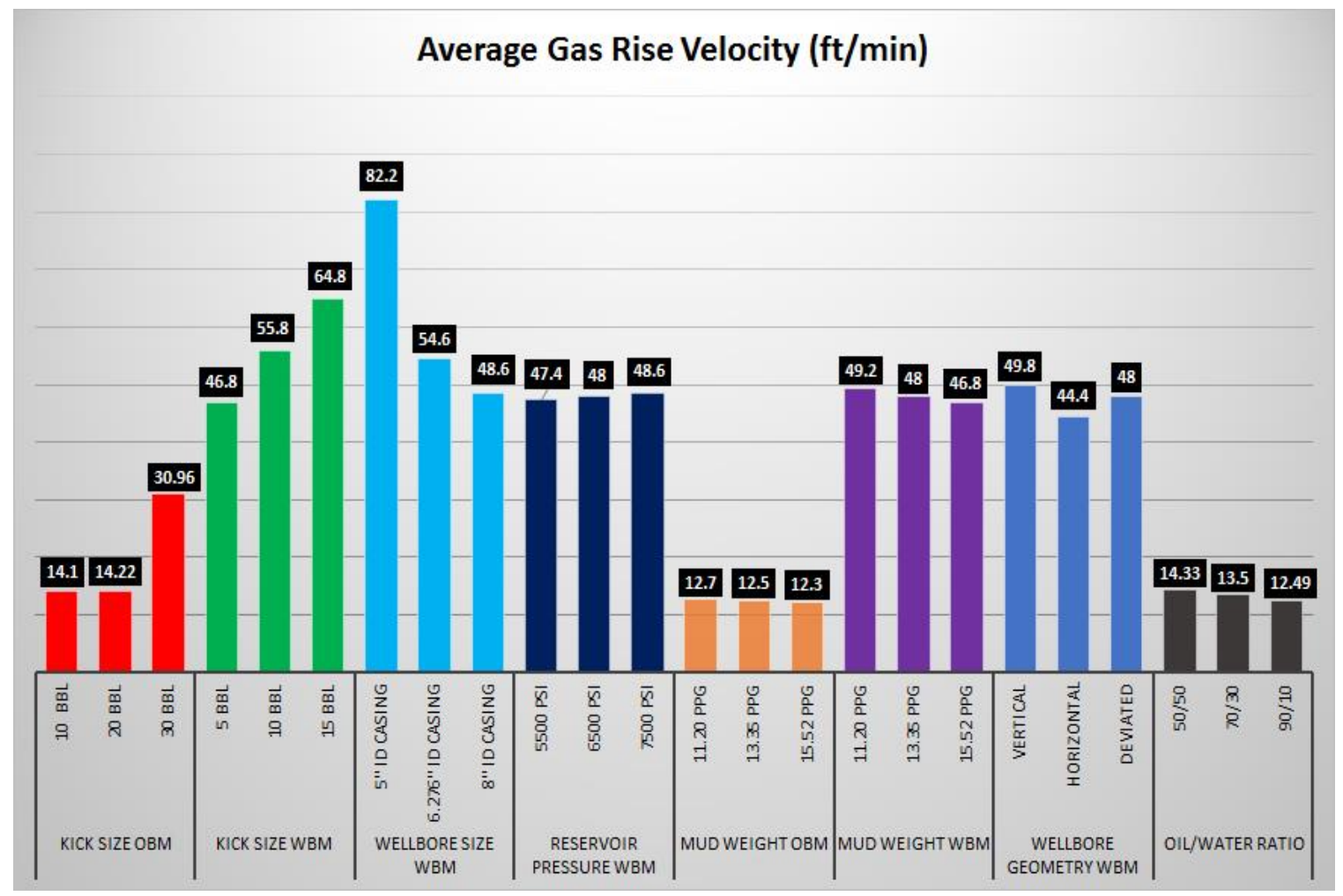

Figure 23 Summary of average gas rise velocities. 


\section{CHAPTER 5}

\section{CONCLUSIONS}

Based on the results and observations of this study, the following conclusions are presented:

- The factors affecting gas rise velocity were kick size, wellbore annulus clearance, reservoir pressure and temperature, wellbore geometry, drilling fluid type, mud density, and oil-water ratio.

- For the wellbore conditions considered in this study, the range of average gas rise velocity for a WBM was between $44 \mathrm{ft} / \mathrm{min}$ and $82.2 \mathrm{ft} / \mathrm{min}$ and the range of average gas rise velocity for OBM was between $12.3 \mathrm{ft} / \mathrm{min}$ and $31.96 \mathrm{ft} / \mathrm{min}$.

- In a closed wellbore during the gas migration; choke, casing shoe, and bottomhole pressures increase and may exceed safety margins.

- Wellbore annular area had a critical impact on the surface choke pressure and gas rise velocity because smaller annular area creates longer gas bubble height causing higher surface pressures with the largest gas rise velocity.

- The kick size has to be considered as a vital parameter on well control operations since larger kick sizes caused higher choke pressures at the surface and higher gas rise velocities, which shortened the migration time of kick to the top of the well.

-With gas going into solution in OBM, there was pressure build-up until all the gas was dissolved and there was no further gas migration. However, gas kick migrated in WBM, and caused the pressure to build-up until gas reached the surface. Therefore, the type of drilling fluid employed has a great impact on annular wellbore pressures.

- The deviation angle affects wellbore pressures. Pressure builds up more in deviated wells, but less in horizontal wells.

- The degree of gas solubility decreased as the temperature increased. Higher 
temperatures caused bigger kick sizes at the downhole and increased choke pressure when OBM used.

- Oil/Water ratio influenced the degree of gas solubility in OBM. The higher was the OWR, the higher was the gas solubility, which affected final dissolution depth of gas in OBM.

- The yield point and plastic viscosity of the drilling fluid had minor impact on wellbore pressures and gas rise velocities in a closed wellbore annulus. 


\section{REFERENCES}

Adams, N. and Kuhlman, L. 1994. Kicks and blowout control: Pennwell Corp.

ASME Shale Shaker Committee. Drilling fluids processing handbook. Elsevier, 2011.

Beggs, D.H. and Brill, J.P. 1973. A study of two-phase flow in inclined pipes. Journal of Petroleum Technology 25 (05): 607-17.

Berthezene, N., De Hemptinne, J., Audibert, A. and Argillier, J.F. 1999. Methane solubility in synthetic oil-based drilling muds. Journal of Petroleum Science and Engineering 23 (2): 71-81.

Choe, J. 2001. Advanced Two-Phase Well Control Analysis (May). Journal of Canadian Petroleum Technology 40 (05).

Drillbench Dynamic Drilling Simulation Software, Schlumberger.

Elshehabi, T. and Bilgesu, I. 2015. Impact of Drilling with Oil Based Mud on Well Control in Horizontal Shale Gas Wells. Presented at the SPE Eastern Regional Meeting.

Fjelde, K.K., Froyen, J. and Ghauri, A.A. 2016, April 20. A Numerical Study of Gas Kick Migration Velocities and Uncertanity. , Bergen, Norway 10.2118/180053-MS.

Fjelde, K., Frøyen, J. and Ghauri, A. 2016. A Numerical Study of Gas Kick Migration Velocities and Uncertainty. Presented at the SPE Bergen One Day Seminar.

Gould, T.L., Tek, M.R. and Katz, D.L. 1974. Two-phase flow through vertical, inclined, or curved pipe. Journal of Petroleum Technology 26 (08): 915-26.

Guner, S., Elshehabi, T. and Bilgesü, H.i 2016. Pressure Variations Due to Migration of Gas Kick Bubbles in Deep Vertical, Deviated and Horizontal Wells.

Hasan, A.R., Kabir, C.S. and Wang, X. 2009. A robust steady-state model for flowing-fluid temperature in complex wells. SPE Production \& Operations 24 (02): 269-76.

Hovland, F. and Rommetveit, R. 1992. Analysis of gas-rise velocities from full-scale kick experiments. Presented at the SPE Annual Technical Conference and Exhibition.

Imomoh, E. 2013. Innovation: Innovative Drilling Operations. Journal of Petroleum Technology 65 (01): 14-6.

Johnson, A. and Cooper, S. 1993. Gas migration velocities during gas kicks in deviated wells. Presented at the SPE Annual Technical Conference and Exhibition.

Johnson, A., Rezmer-Cooper, I., Bailey, T. et al. 1995. Gas migration: Fast, slow or stopped.

Presented at the SPE/IADC Drilling Conference. 
Maia, F.D.A. and Lima, H.R. 2012. ICS Command System-Blowout Response. Presented the International Conference on Health, Safety and Environment in Oil and Gas Exploration and Production.

Mason, S., Chandrasekhar and S., May 2015. Stochastic Kick Load Modelling. , Woodlands,TX 10.2118/97564-MS.

Matthews, J. and Bourgoyne Jr, A. 1983. Techniques for Handling Upward Migration of Gas Kicks in a Shut-In Well. Presented at the IADC/SPE Drilling Conference.

Monteiro, E. 2005. Study of Methane Solubility in Organic Emulsions Applied to Drilling Fluid Formulation and Well Control. Presented at the SPE Annual Technical Conference and Exhibition.

Ng, F. 2005. Well Control Simulation - A Tool for Engineering and Operations. Presented at the National Technical Conference and Exhibition, Houston, Texas, April 5-7. AADE-05-NTCE-51.

O'Bryan, P.L., Bourgoyne Jr, A.T., Monger, T.G. and Kopsco, D.P., 1988. An experimental study of gas solubility in oil-based drilling fluids. SPE drilling engineering 3 (01): 33-42.

Rader, D.W., Bourgoyne, A.T. and Ward, R.H. 1985. Factors Affecting Bubble-Rise Velocity of Gas Kicks. Society of Petroleum Engineers. doi: 10.2118/4647-PA.

Savari, S. and Kumar, A. 2012. Wellbore integrity management: Dealing with uncertainties. Presented at the SPE Oil and Gas India Conference and Exhibition.

Shen, Z., Ling, K. and He, J. 2013. A Rigorous Method to Calculate the Rising Speed of Gas Kick. Presented at the SPE Unconventional Gas Conference and Exhibition.

Stromsnes, O., Stakkeland, H. and Pedersen, S. 1995. Cost reduction and safety improvement through integrated drilling operations. Presented at the SPE Annual Technical Conference and Exhibition.

Sutton, I.S. 2013. Summarizing the deepwater horizon/macondo reports. Presented at the Offshore technology conference.

Thomas, D.C., Lea Jr, J.F. and Turek, E. 1984. Gas solubility in oil-based drilling fluids: Effects on kick detection. Journal of Petroleum Technology 36 (06): 959-68.

Veeningen, D. 2013. Detect Kicks Prompted by Losses and Direct Measurement Well Control Method through Networked Drillstring with Along String Pressure Evaluation. Presented at the SPE/IADC Drilling Conference.

Velmurugan, N., Godhavn, J. and Hauge, E. 2016. Dynamic Simulation of Gas Migration in Marine Risers. Presented at the SPE Bergen One Day Seminar. 
Watson, D., Brittenham, T. and Moore, P. 2003. Advanced Well Control, Vol. 10. Richardson, Texas: Textbook Series, SPE .

\section{APPENDIX}

\section{A-1 Example of Modelling in the Simulator}

An example case of this study is presented in this section. The modelling of the dynamic well control simulator is presented in a stepwise fashion. The example uses a reservoir pressure of 5500 psi in a horizontal well. Figure 24 shows the summary of well geometry, drilling fluid, reservoir description, and surface equipment in the summary window of the simulator.

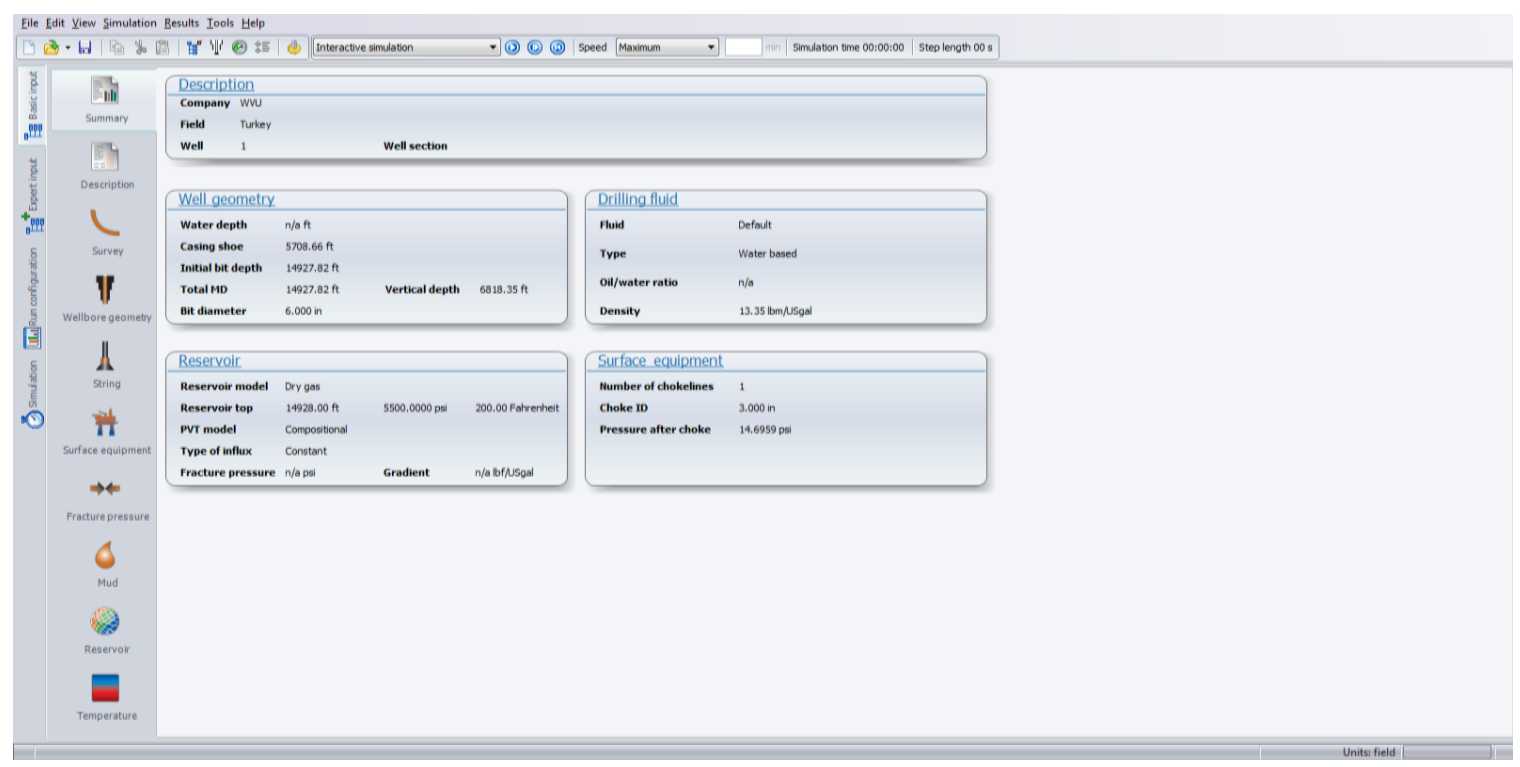

Figure 24 Initial screen of the simulator.

Figure 25 shows the simulator page to enter survey data for the wellbore. Survey data is used to create vertical, deviated and horizontal wellbore trajectories. Kick off point (KOP) of horizontal well is adjusted in this section. KOP of the horizontal example well was set to $4757 \mathrm{ft}$. and a measured depth of $14927 \mathrm{ft}$ was used. 


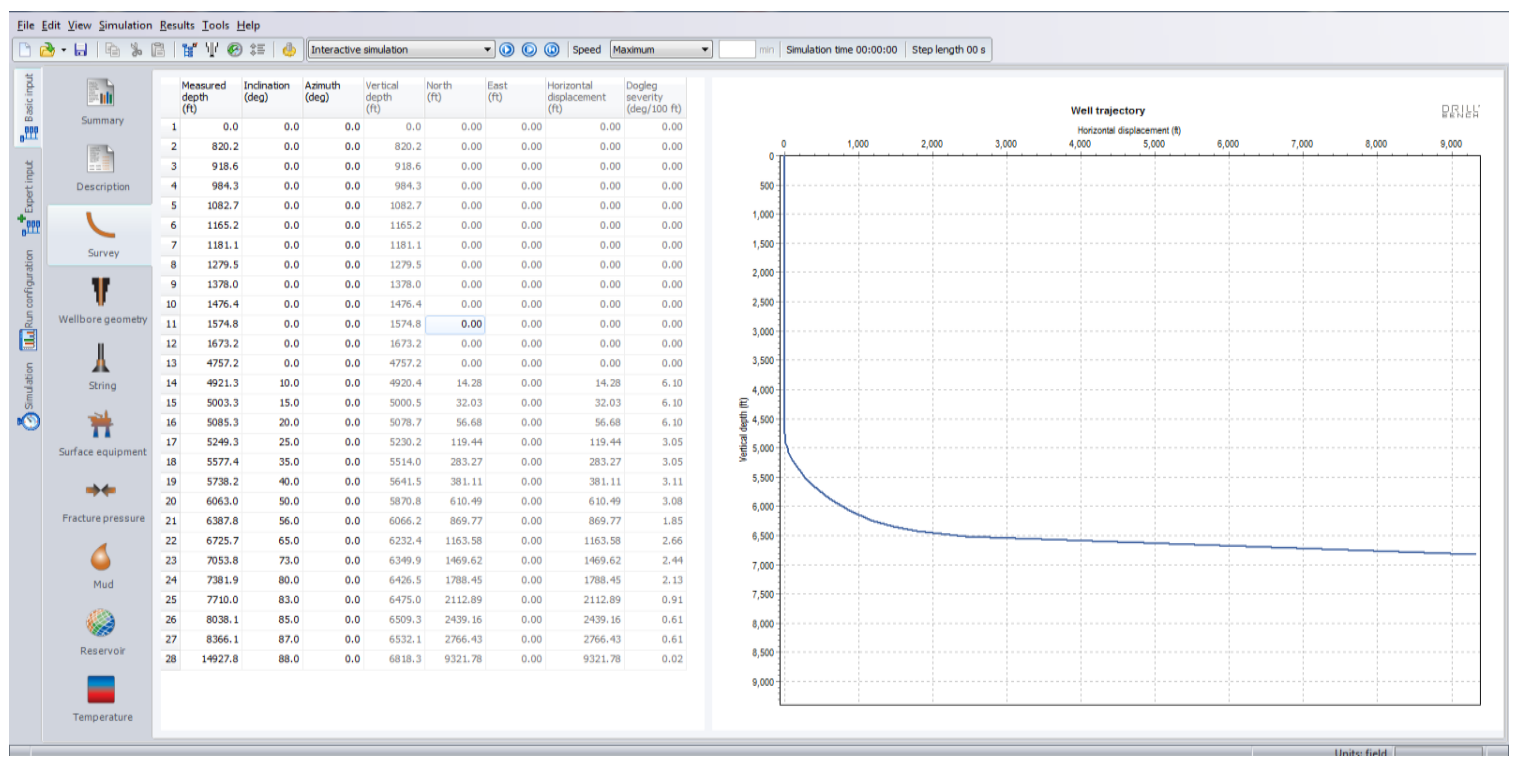

Figure 25 Wellbore directional survey option.

Wellbore geometry option shown in Figure 26 is used to select the wellbore completion options as a cased or open hole. In this example a 7 -in. OD casing set at $5708 \mathrm{ft}$ was selected.

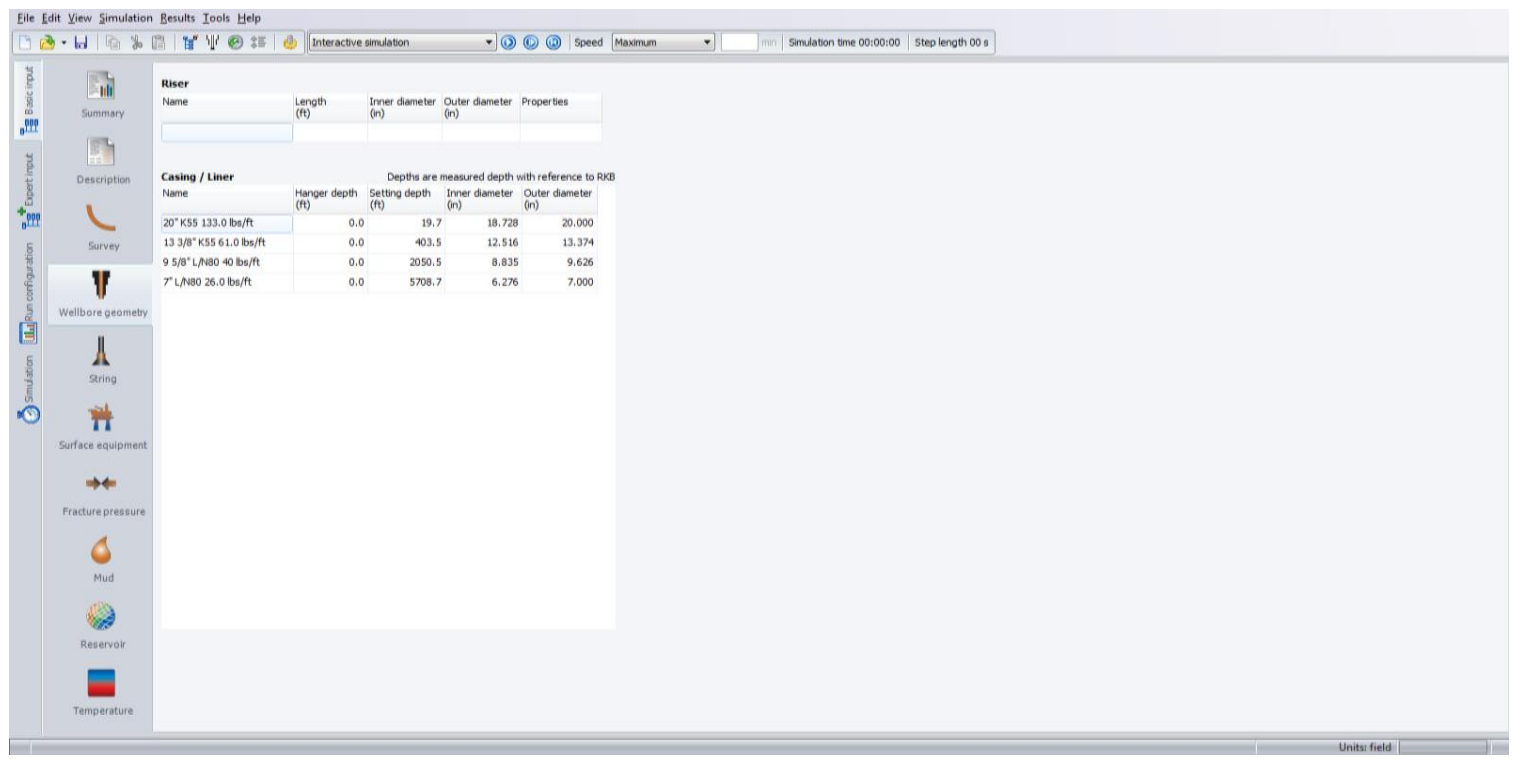

Figure 26 Casing/liner selection. 
Drill string with desired bottom hole assembly (BHA) is selected using the string option as shown in Figure 27. Selection includes type and length of drill pipe and drill collars, bit size and nozzle diameter. Since measured depth of the well was $14927 \mathrm{ft}$, the length of BHA is adjusted to the same length of the well.

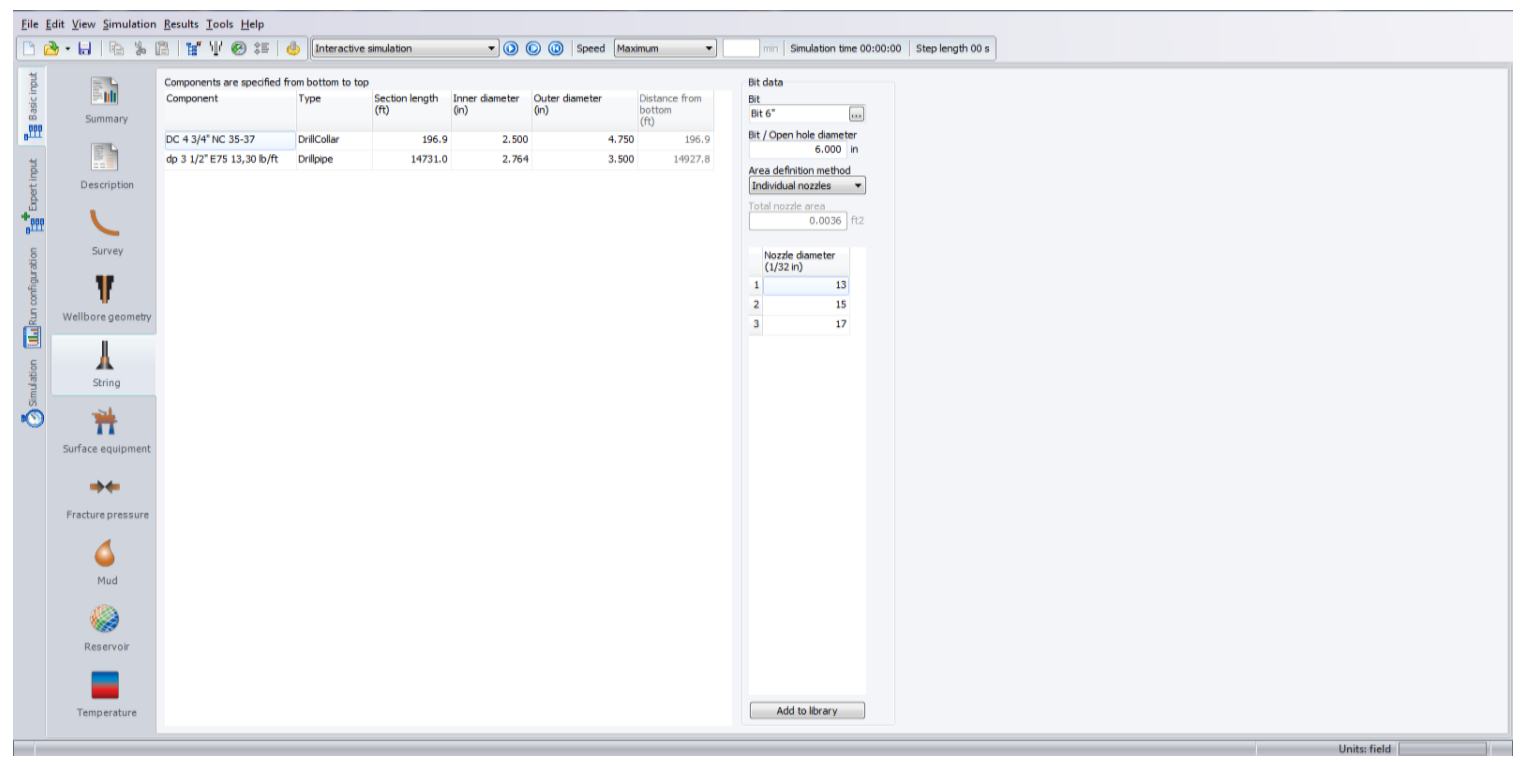

Figure 27 Drill string and BHA selection.

Figure 28 shows the options for surface equipment window which includes choke diameter and line length, pump and BOP specifications, and surface annulus pressure. 


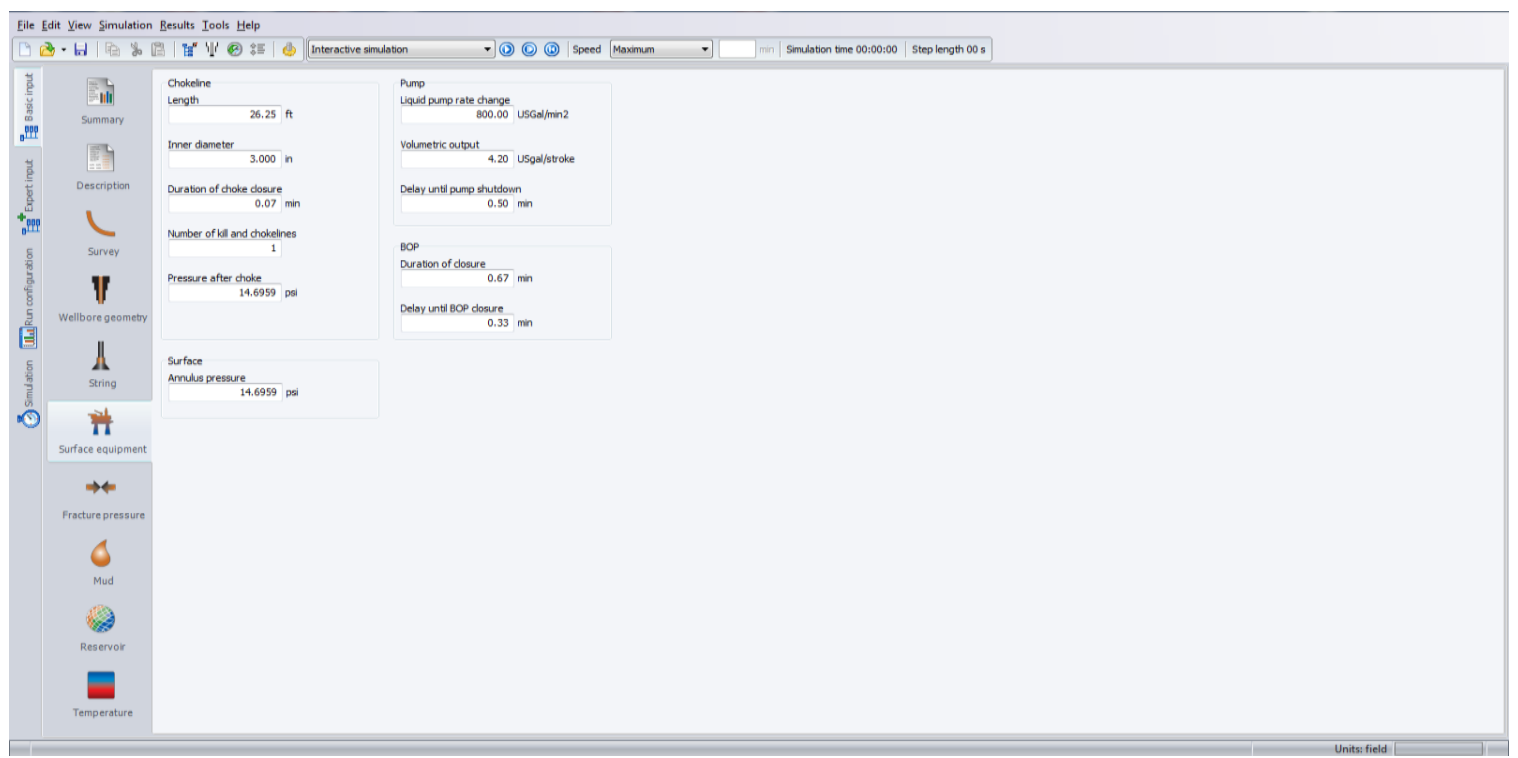

Figure 28 Surface equipment selection

Figure 29 shows the data needed for the fracture pressure as a function of depth. In this example fracture pressure gradient was not used in order to prevent fracturing the formation, which can affect the investigation of wellbore pressures during gas migration.

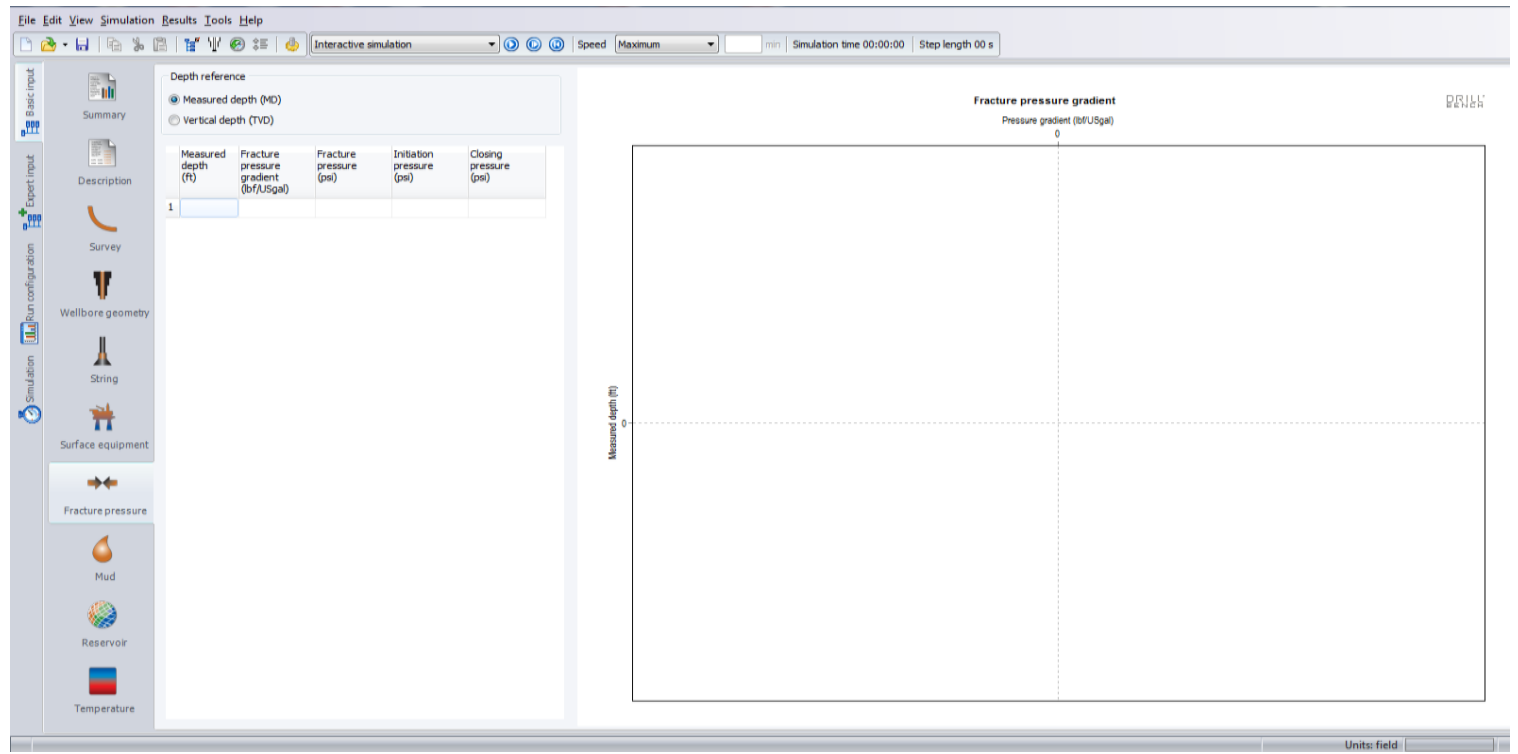

Figure 29 Formation fracture pressure data. 
Properties of drilling fluid used by the program are entered using mud option (Figure 30). Several parameters are needed to model the behavior of drilling fluid. Input data includes density, temperature, oil-water-ratio, Fann readings and rheological model.

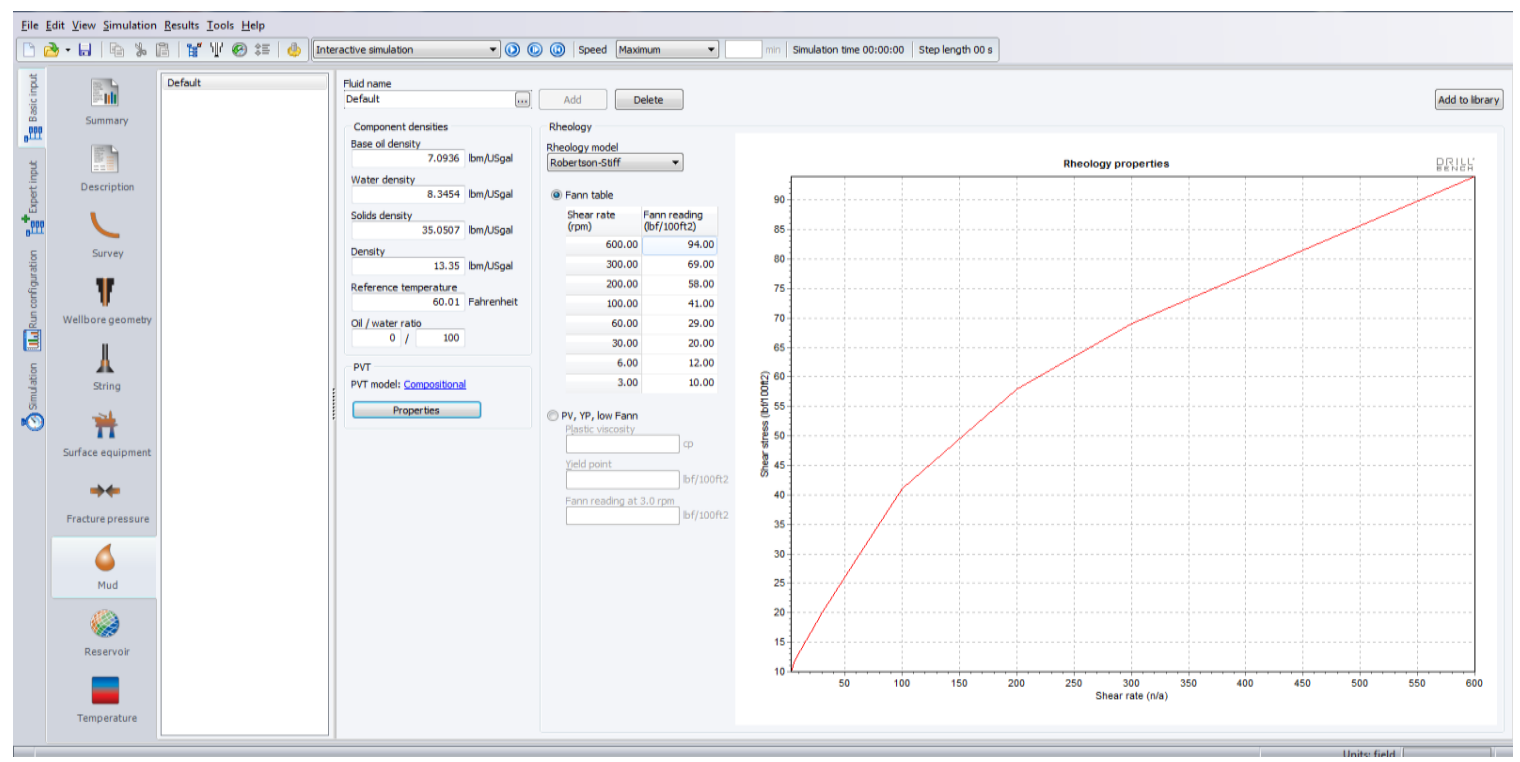

Figure 30 Required drilling fluid properties.

Reservoir parameters for each subsurface formation, such as depth intervals , temperature, pressure, permeability and porosity, kick influx rate, and reservoir fluid type are entered to the program using the reservoir tab show in Fogure 31. 


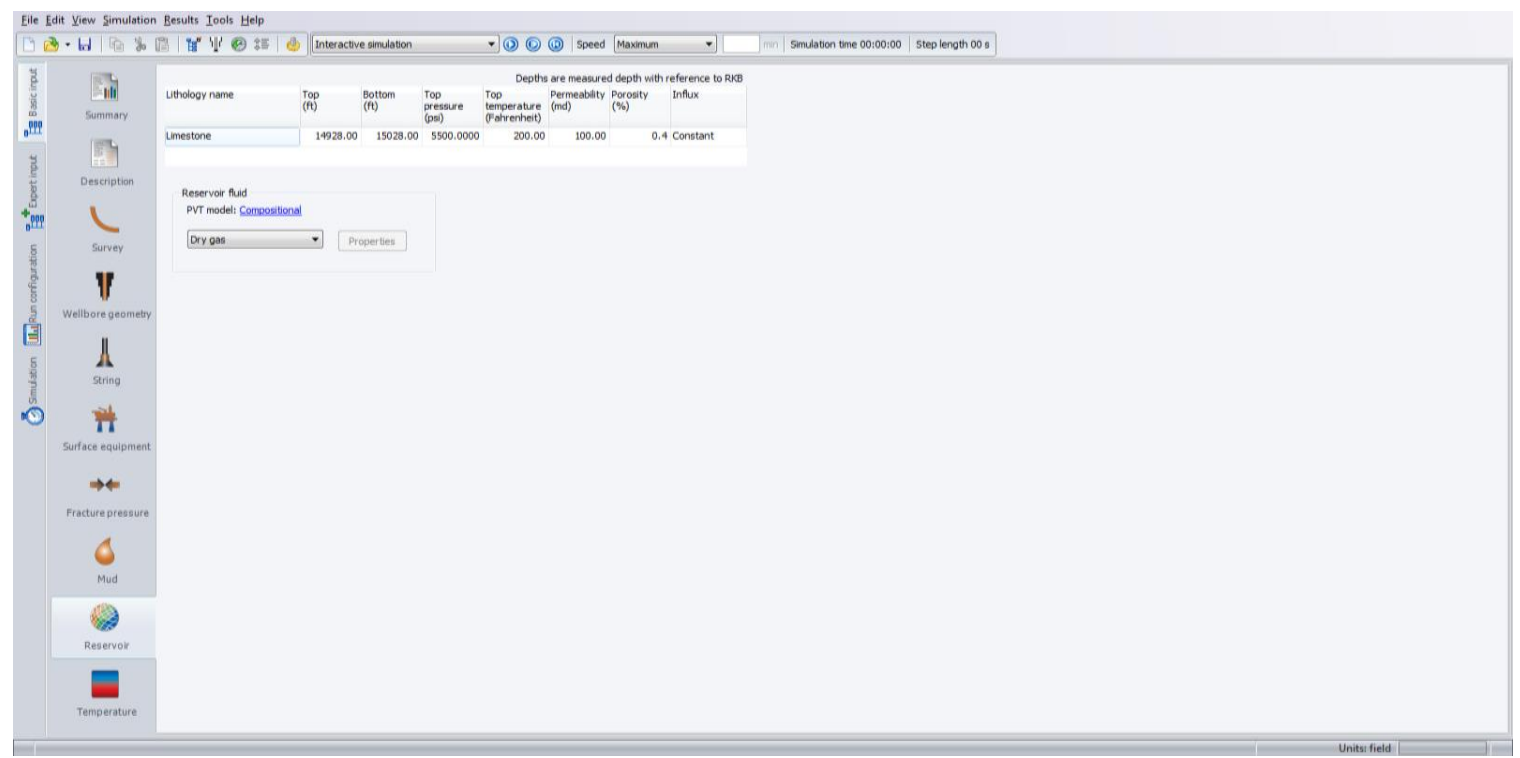

Figure 31 Reservoir data requirement.

Mud temperature in drill string and in annulus at the surface and at the bottom are selected using temperature window (Figure 32). In this example, mud annulus temperature at the bottom hole was set to $200^{\circ} \mathrm{F}$, which was the same temperature as the reservoir temperature.

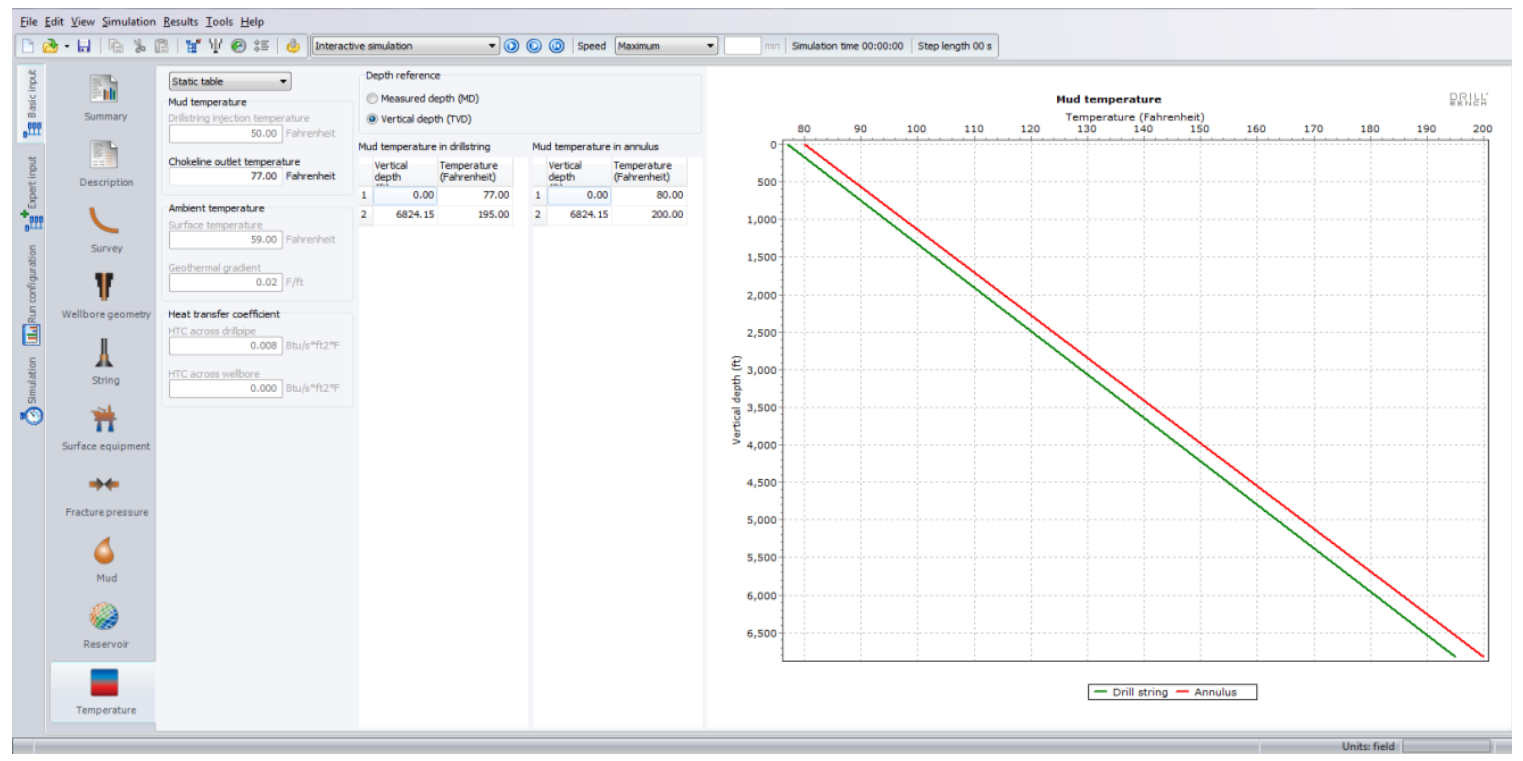

Figure 32 Reservoir temperature assignment. 
Runs are conducted after setting all needed model parameters. While running the model, results can be monitored at the simulation window. The properties monitored are pit gain, pump pressure, gas flow rate, choke pressure, free gas volume fraction, dissolved gas mass fraction, casing shoe pressure and pit volume gain (Figure 33)

choke pressure, bottom hole pressure, casing shoe pressure, pit gain and total influx figures are monitored for each case in this study (Figure 33).

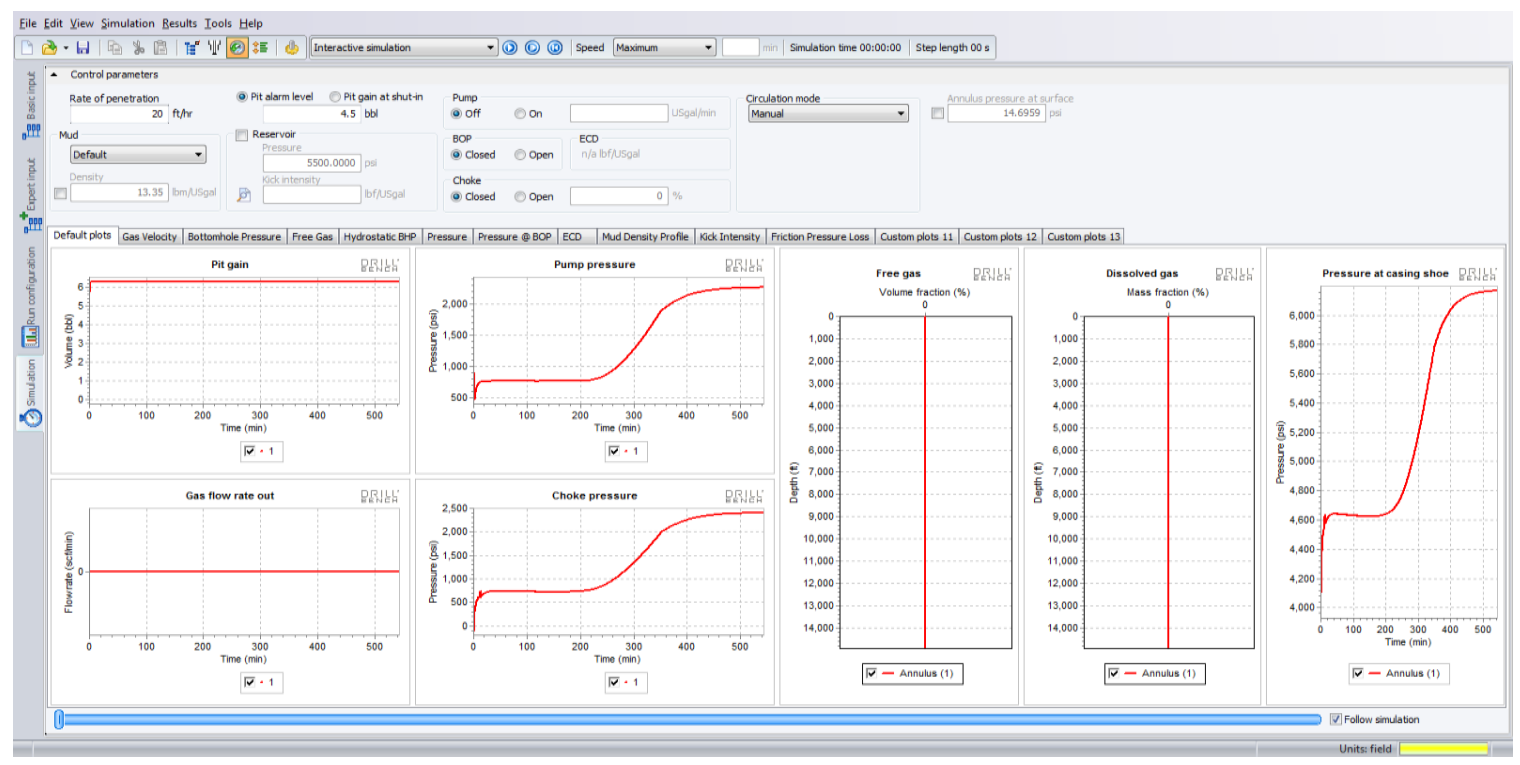

Figure 33 Monitored parameters during simulations. 


\section{A-2 3-D View of Horizontal, Deviated, and Vertical Well}

Figure 34 shows the 3-D view of horizontal, deviated, and vertical wells used to study the impact of wellbore geometry.

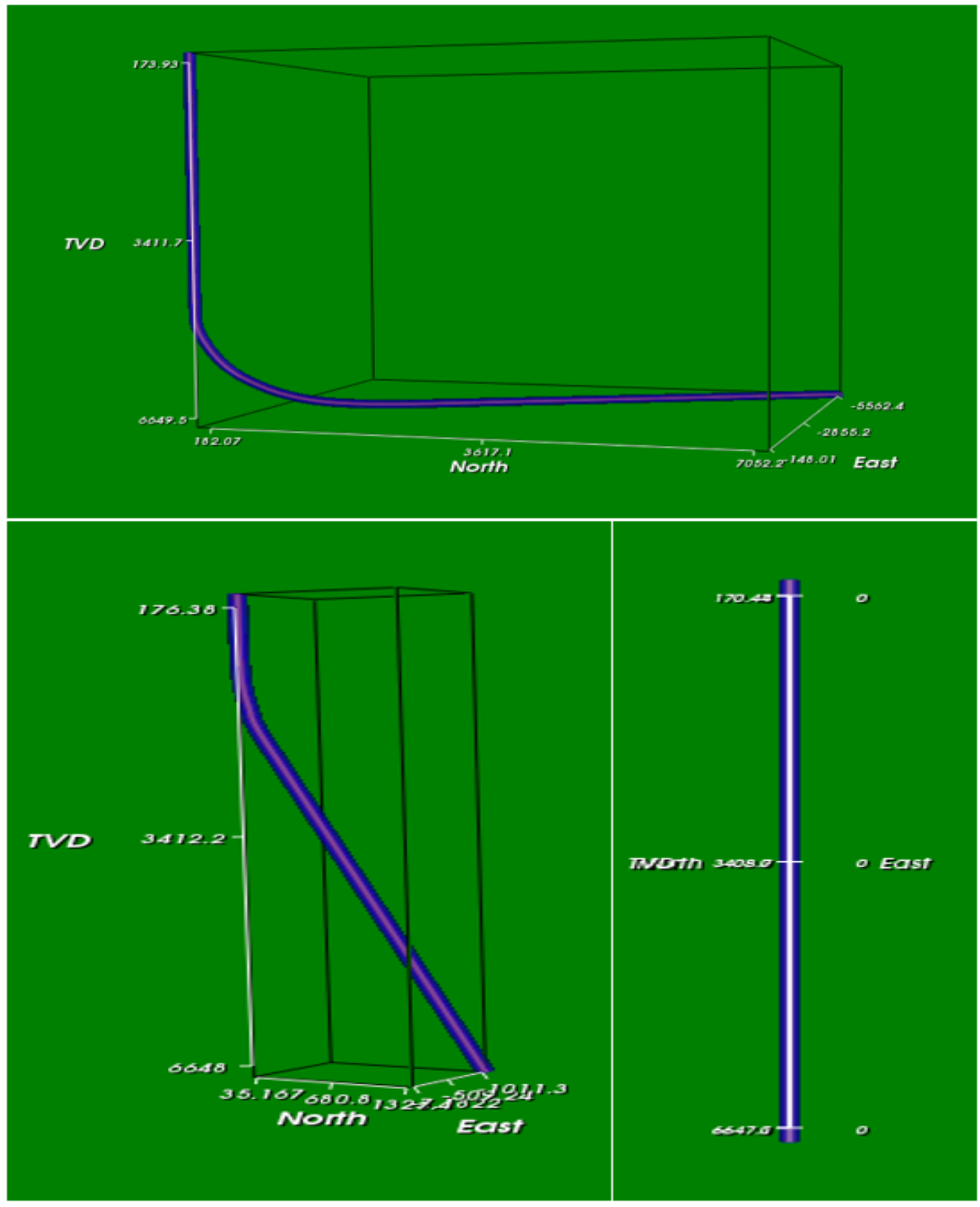

Figure 34 3-D view of horizontal, deviated, and vertical well trajectories (DrillBench) 


\section{A-3 Mud Plastic Viscosity and Yield Point Calculations}

Figure 35 represents the range of possible yield points and plastic viscosities of mud according to its weight. The upper curve on the left represents the maximum values of YP, and the lower curve represents the minimum values of YP for the selected mud weight. Similarly, curve on the right gives range of plastic viscosity values for a given mud density. Since 13.35 ppg mud was used, three different YP values were used between the maximum and minimum $\left(5,10\right.$, and $\left.15 \mathrm{lbm} / 100 \mathrm{ft}^{2}\right)$ to evaluate the effect of YP on wellbore pressures and gas rise velocities while keeping plastic viscosity and mud weight constant. PV values for 13.35 ppg mud were selected by considering the maximum and minimum value of $\mathrm{PV}$ in Figure 35 below.

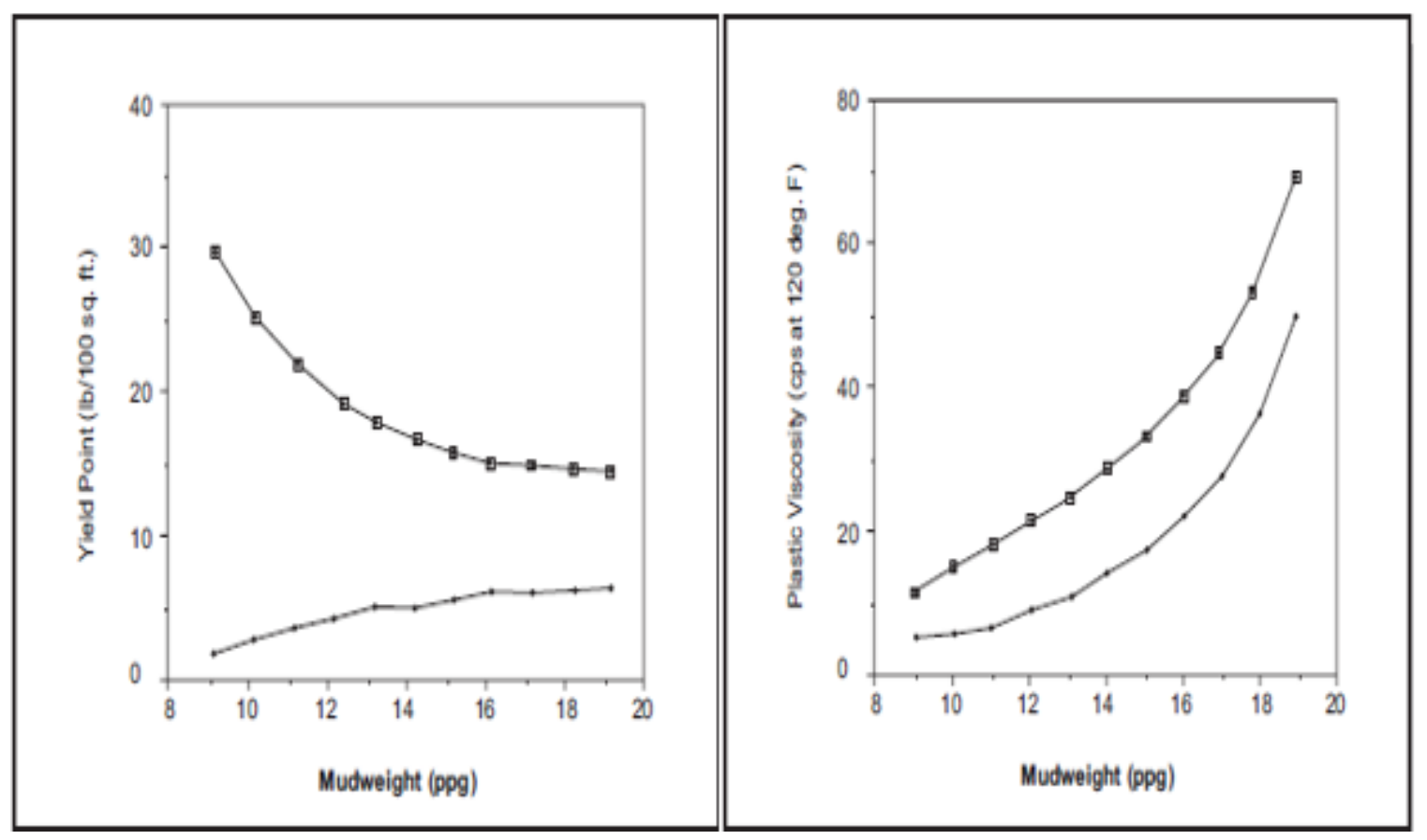

Figure 35 Range of YP and PV for a given mud weight (ASME Shale Shaker Committee, 2011) 